\title{
Onset of runaway fragmentation of salt marshes
}

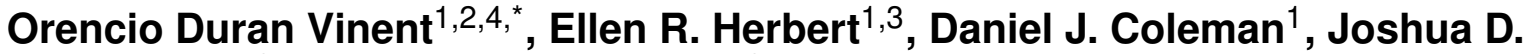 \\ Himmelstein ${ }^{1}$, and Matthew L. Kirwan ${ }^{1}$
}

1Virginia Institute of Marine Sciences, College of William and Mary, Gloucester Point, Virginia 23062, USA
2Texas A\&M University, Department of Ocean Engineering, College Station, Texas 77843, USA
3Ducks Unlimited, Memphis, Tennessee 38129, USA
$\begin{aligned} & { }^{4} \text { Lead Contact } \\ & \text { *Correspondence: oduranvinent@tamu.edu }\end{aligned}$
$\begin{gathered}\text { Post-print of a manuscript published in One Earth } \\ \text { https://doi.org/10.1016/j.oneear.2021.02.013 }\end{gathered}$

SUMMARY

Salt marshes are valuable but vulnerable coastal ecosystems that adapt to relative sea level rise (RSLR) by accumulating organic matter and inorganic sediment. The natural limit of these processes defines a threshold rate of RSLR beyond which marshes drown, resulting in ponding and conversion to open waters. We develop a simplified formulation for sediment transport across marshes to show that pond formation leads to runaway marsh fragmentation, a process characterized by a self-similar hierarchy of pond sizes with power-law distributions. We find the threshold for marsh fragmentation scales primarily with tidal range and that sediment supply is only relevant where tides are sufficient to transport sediment to the marsh interior. Thus the RSLR threshold is controlled by organic accretion in microtidal marshes regardless of the suspended sediment concentration at marsh edge. This explains the observed fragmentation of microtidal marshes and suggests a tipping point for widespread marsh loss.

Keywords: wetland, sea level rise, marsh drowning, accretion, pond, sediment transport, pattern formation

\section{Introduction}

There is a growing consensus that marsh vulnerability to relative sea level rise (RSLR) is tied to inorganic sediment availability ${ }^{1-4}$, where deposition of inorganic sediment increases with flooding duration, and potentially offsets sea level rise. Indeed, inorganic deposition rates have accelerated over the last century concomitant with sea level rise ${ }^{5,6}$ and historic marsh loss has been observed (and projected ${ }^{7,8}$ ) mostly in sediment-poor systems $^{9,10}$ and microtidal marshes ${ }^{11}$. Modeled threshold rates of RSLR for marsh drowning, using simplified point (0-D) models, increase by 2 orders of magnitude as a function of suspended sediment concentration and tidal range ${ }^{12,13}$. However, a contrasting body of work emphasizes the importance of organic matter accumulation in building marsh soils in the face of sea level rise, especially in the sediment deficient estuaries most vulnerable to sea level rise ${ }^{1,11,14-17}$. Total marsh accretion rates are more strongly correlated with the organic fraction of marsh soil than the inorganic fraction ${ }^{14}$; organic matter contributes 4 times more soil volume than an equivalent mass of inorganic sediment ${ }^{16}$; and organic matter is the dominant contribution to marsh accretion by volume in many Atlantic and Gulf Coast marshes ${ }^{14-16}$.

Competing ideas about the relative importance of organic and inorganic accretion likely reflect strong spatial gradients within marshes ${ }^{18-20}$. Inorganic accretion increases with suspended sediment concentration and flooding depth, and decreases with distance to tidal channels, as reported both in the field ${ }^{21-25}$ and in models ${ }^{18-20,25-29}$. Organic accretion is influenced by the production and decomposition of plant biomass, both of which vary spatially across marshes in response to flooding depth as well as other factors. Moreover, vegetation itself enhances inorganic sediment deposition so that organic and inorganic contributions are thoroughly inter- twined $^{30,31}$. These spatial gradients of organic and inorganic deposition lead to complex patterns of marsh accretion and submergence that are sometimes difficult to explain. For example, marshes along the Blackwater River (MD, USA) are rapidly submerging despite having a higher suspended sediment concentrations measured in channels, than in nearby stable marshland ${ }^{32,33}$. Elsewhere, marshes are submerging despite measured accretion rates that are similar to or exceed $\mathrm{RSLR}^{2,33}$, which suggests measurements take place mostly along marsh edges, where maximum accretion rates are generally observed $21,23,34,35$.

The complexity of organic and inorganic accretion in a marsh platform leads to the simple question: where in a marsh should organic and inorganic contributions to marsh accretion be characterized to best evaluate marsh vulnerability to RSLR? Measurements from high elevation portions of a marsh potentially underestimate future marsh accretion because inorganic accretion rates may accelerate with increased flooding duration ${ }^{2}$. However, if low elevation marshes are also closest to channels, then accretion rates from low elevation portions of the marsh would overestimate accretion to the marsh as a whole, and lead to an underestimation of marsh vulnerability to RSLR.

Another issue with the interpretation of measured accretion rates is that they tend to converge towards the local rate of RSLR, as the marsh platform approaches an equilibrium elevation $^{36}$, which complicates the estimation of maximum accretion rates unless marshes are already drowning 2,37 . Thus, there is a need for better numerical models that resolve the spatial complexity of marsh sediment dynamics $4,13,19,27,28,38-40$.

A few existing process-based models (e.g. ${ }^{19,28}$ ) capture the observed drowning of interior marshes and their conversion to ponds ${ }^{41-43}$. They suggest marsh drowning, and subsequent 
pond formation, is not described by a single threshold but is instead a gradual process where different portions of the marsh platform drown at different rates of RSLR. Therefore, existing models with RSLR rates just slightly faster than the threshold for drowning would produce an equilibrium state characterized by relatively few, isolated ponds, far from the channel edge.

Here, we uniquely show that there is no equilibrium state for a marsh platform once a local threshold for marsh drowning has been crossed, resulting in runaway marsh fragmentation. Theoretical considerations and field observations indicate that the threshold for marsh drowning does not change much with sediment supply in microtidal marshes, suggesting a disproportionate role of organic accretion.

\section{Model approach}

We use a one-dimensional formulation for the mass conservation of water and inorganic sediments in the absence of erosion $4,27,28,38,39,44$, to derive a minimal sediment transport model that captures the central physics of the system (the complete model is described in the Experimental Procedures; see Figs. S1 and S2 for examples of the solutions). This simplified model allows us to define and calculate the drowning threshold and characterize the dynamics of the ensuing marsh fragmentation without the need of spatially-explicit hydrodynamic models $26,27,29,39,45$.

The current understanding of the onset of marsh loss is that it takes place whenever marsh depth relative to mean high water is higher than a critical value $D_{c}$ above which marshes are replaced by tidal flats or ponds as the more stable morphology $43,46-49$. Indeed, field data suggests marsh conversion to tidal flats starts at a critical depth $D_{c}$ around $35 \%$ of the tidal range $\delta z$, which corresponds to an average rescaled inundation time, i.e. fraction of time the marsh is submerged $\tau_{c} \approx \pi^{-1} \arccos \left(1-2 D_{c} / \delta z\right.$ ), of about 0.4 (Fig. 1B, see Table S1 for details $)^{42,43,46-48}$.

Assuming the existence of a critical depth for marsh recovery, a general condition for the onset of local marsh drowning is when the rate $R$ of RSLR exceeds the sum of the organic $\left(A_{o}^{c}\right)$ and inorganic $\left(A_{i}^{c}\right)$ accretion rates evaluated at the critical depth $D_{c}$ (Fig. 1A). Because of the spatial variation of inorganic deposition, the lowest inorganic accretion rate at the critical depth thus defines the lowest threshold $\left(R_{c}\right)$ for local marsh drowning: $R_{c}=A_{o}^{c}+\min \left\{A_{i}^{c}\right\}$.

We derive a general expression for $R_{C}$ from a simplified model of the inorganic accretion rate $A_{i}(x, D)$ across a marsh platform with variable depth $D(x)$, as function of the distance $x$ to the sediment sources. In the absence of erosion, we assume $A_{i}(x, D)$ can be written in terms of the depthdependent rescaled average inundation time $\tau(D)$ and the depth-independent sediment concentration $\bar{C}(x)$, as $A_{i}(x, D)=$ $\rho_{i}^{-1} w_{f} \tau(D) \bar{C}(x)$, where $\rho_{i}$ is an average density of deposited sediments ${ }^{1}, w_{f}$ is an effective settling velocity and $\bar{C}$ is defined as the local depth-averaged suspended sediment concentration (SSC) averaged over times of positive water depths in a tidal cycle (see Experimental Procedures).

In what follows we present and validate an explicit expression for the inorganic accretion rate across the marsh platform and use it to obtain the critical inorganic accretion rate for marsh drowning. We then introduce the drowning threshold, characterize the runaway marsh fragmentation regime and discuss the effect of external parameters on marsh drowning.

\section{Results}

\section{Exponential decay of sediment concentration}

As inorganic sediments in the water column settle on the marsh surface, where erosion is assumed to be negligible ${ }^{27}$, the averaged sediment concentration $\bar{C}$ decays with the distance $x$ from the channel or tidal flat (Fig. 2). Sediment concentration thus reaches its lowest value at the location furthest away-a distance $L$-from marsh edges (Fig. 2A), defined in the model as the watershed divide. This decay in sediment concentration is well approximated by an exponential function, $\bar{C}(x)=\bar{C}(0) e^{-x / L_{c}}$ (as proposed by ${ }^{25}$ and observed by ${ }^{23}$ ), with decay length $L_{c}$ (see Experimental Procedures). Therefore, the inorganic accretion rate for a non-flat marsh platform can be approximated as

$$
A_{i}(x, D(x)) \approx \rho_{i}^{-1} w_{f} \tau(D(x)) \bar{C}(0) e^{-x / L_{c}},
$$

where the average sediment concentration $\bar{C}(0)$ at the channel bank or marsh edge is proportional to the average concentration $C_{0}$ at the channel or mud flat during flood (see Fig. S3 for the proportionality factor).

The decay length $L_{c}$ of the average suspended sediment concentration scales as the ratio of the tidal discharge per unit width and the effective sediment settling velocity $w_{f}$, in agreement with the scaling of the deposition length in unidirectional turbulent suspensions ${ }^{50}$ (Experimental Procedures). We find tidal discharge per unit width scales as $L \delta z / T$, where $\delta z$ is the tidal range, $T$ is the tidal period and $L$ is the characteristic length of the local drainage basin. Thus, the decay length has the form

$$
L_{c}=\beta L \delta z /\left(T w_{f}\right),
$$

with fitting parameter $\beta \approx 1.5$, in agreement with both numerical simulations and analytical approximations (Experimental Procedures and Fig. 2B).

We find the exponential approximation accurately describes the sediment concentration profile except in the region around the watershed divide, where tidal flow stops and the simulated average sediment concentration, and thus accretion rates, converge to zero (Fig. 2). In reality, complex tidal flows may lead to residual accretion rates in the marsh interior (e.g. ${ }^{22}$ ), in which case the exponential approximation provides an upper limit to evaluate the resiliency of drowning marshes. In what follows we use the watershed divide as a formal definition of the marsh interior.

The exponential decay correctly predicts the spatial gradient in the average sediment concentration and inorganic accretion rates for a wide variety of salt marshes (Fig. 3), including lowelevation micro-tidal marshes in the Virginia eastern shore (Phillips Creek) $^{34}$ and Georgia ${ }^{35}$, and meso- and macro-tidal marshes in Plum Island, MA ${ }^{51}$, Norfolk, $\mathrm{UK}^{21}$ and in the Bay of Fundy, $\mathrm{CA}^{52}$ (see Experimental Procedures for further details on the analysis and interpretation of inorganic accretion data).

The scaling of $L_{c}$ with the tidal range $\delta z$ (Eq. 2) means that suspended sediments deposit closer to channels (or tidal flats) at lower tidal ranges, whereas they are more homogeneously distributed at higher tidal ranges. This is consistent with the 
trend observed in field measurements (Fig. 3), in particular the contrast between the almost homogeneous inorganic accretion in the Bay of Fundy, $\mathrm{CA}^{52}(\delta z=11 \mathrm{~m})$, and the noticeable decay observed in Phillips Creek, US ${ }^{25}(\delta z=2 \mathrm{~m})$.

\section{Critical inorganic accretion rate}

The scaling of the sediment decay length $L_{c}$ with the local drainage basin length $L$ (Eq. 2) follows from the approximate scale invariance of tidal flows ${ }^{44}$, i.e. faster flows-and increasing sediment advection-on larger basins. This scale invariance, where sediments are deposited farther away from the channels in large basins as compared to small ones (Fig. S4), has one important implication: the lowest inorganic accretion rate at the critical depth $D_{c}$ for marsh conversion to tidal flats $A_{i}^{c}(L) \equiv A_{i}\left(L, D_{c}\right)$, reached at the watershed divide $x=L$ (Eq. 1), does not depend on drainage basin size $L$ and can be evaluated without the need of spatially-explicit hydrodynamic models. Indeed, after substituting the scaling for the decay length we get for the critical inorganic accretion rate:

$$
A_{i}^{c}(L)=A_{i}^{c}(0) e^{-1 / \ell_{c}},
$$

where $\ell_{c}=L_{c} / L=\beta / w_{f}^{+}$is the rescaled decay length, which only depends on the rescaled effective falling velocity $w_{f}^{+}=$ $w_{f} T / \delta z$, and $A_{i}^{c}(0) \equiv A_{i}\left(0, D_{c}\right)$ is the inorganic accretion rate at the critical depth in the marsh edge (Eq. 1). Using the scaling $\bar{C}(0)=r\left(w_{f}^{+}\right) C_{0}$ we find for the flood-ebb average sediment concentration at the marsh edge (see Experimental Procedures), we get the explicit expression

$$
A_{i}^{c}(0)=\rho_{i}^{-1} C_{0} w_{f} r\left(w_{f}^{+}\right) \tau_{c},
$$

with $\tau_{c} \equiv \tau\left(D_{c}\right)$. Thus, the critical inorganic accretion rate (Eq. 3 ) is completely determined by external, measurable parameters, characterizing sediment supply to the marsh $\left(C_{0}\right)$, effective sediment properties $\left(w_{f}\right.$ and $\left.\rho_{i}\right)$ and tides $(\delta z$ and $T)$.

An important consequence of the physical mechanisms driving sediment redistribution across the marsh platform, as summarized in Eq. 3, is that the critical inorganic accretion rate strongly depends on the tidal range (Fig. 4). For typical values of the parameters, $A_{i}^{c}(L)$ becomes negligible for tidal ranges $\delta z<1 \mathrm{~m}$ regardless of the sediment supply (Fig. 4), in stark contrast to the critical inorganic accretion rate at the marsh edge $A_{i}^{c}(0)$ (Fig. 4A). More generally, for most microtidal marshes $(\delta z<1.5 \mathrm{~m})$ the predicted critical accretion rate in the marsh interior $\left(A_{i}^{c}(L)\right)$ is below common rates of RSLR (2.5$5 \mathrm{~mm} / \mathrm{yr}$ ) (Fig. 4B) and organic accretion becomes crucial for marsh survival.

\section{Threshold for marsh drowning and the onset of runaway marsh fragmentation}

The marsh accretion rate at the critical depth in the marsh interior, $A_{o}^{c}+A_{i}^{c}(L)$, defines the lowest threshold for marsh drowning $R_{c}$ (Fig. 5A). When relative sea level rises at a lower rate $\left(R<R_{c}\right)$, marshes are stable by definition and bare areas with an elevation above the critical depth can recover with time $^{42}$. When relative sea level rises at a faster rate $\left(R>R_{c}\right)$, interior marshes drown and form permanent ponds.

Simulations of the time evolution of marsh elevation $Z(x, t)$ (see Experimental Procedures for model details), show marsh fragmentation regime strongly depends on whether permanent ponds are isolated or connected to the channel network (Fig. 5A). In the first case, tidal basins and watershed divides remain unchanged and the system evolves towards a new equilibrium state (Fig. 5A, left). The portion of the marsh closer to the edge adapts to RSLR and reaches a non-uniform equilibrium marsh elevation in response to spatial gradients of sediment concentration, e.g. as in the formation of natural levees $^{53}$. We find the equilibrium pond size scales with the size of the local basin and increases with the rate $R$ of RSLR (Fig. 5A left, see Experimental Procedures for pond size calculation).

However, isolated ponds tend to connect to the channel network via the formation of new small channels ${ }^{41,42,49}$, thereby increasing channel density and shrinking tidal basins. Based on this, we assume in our model that once ponds are deep enough they connect to channels and become a source of sediment and tidal flow (see Experimental Procedures). Regardless of the specific conditions for when and how ponds connect, simulations show there is no marsh equilibrium as long as permanent ponds are able to connect to the channel network. Instead, marshes experience a continuous (runaway) fragmentation at a rate controlled by the ratio $R / R_{c}$ (Fig. $5 \mathrm{~A}$, right).

The runaway fragmentation can be understood as follow: although there are more channels (and connected ponds) to potentially redistribute sediments into the marsh platform, the sediment will be deposited closer to the banks as water flow slows down in the now smaller basins (see Eq. 2). As a result, the drowning threshold $R_{c}=A_{o}^{c}+A_{i}^{c}(L)$ is crossed around the watershed divide of the new system, leading to marsh drowning at ever smaller scales. Therefore, with time, marsh fragmentation propagates from large to small scales following the adjustment of the channel network and tidal flows, until most of the marsh is lost.

We can obtain an upper-bound for the threshold rate of RSLR for the onset of runaway marsh fragmentation $\left(R_{c}=\right.$ $A_{o}^{c}+A_{i}^{c}(L)$, Fig. 6) using a theoretical estimation of the maximum contribution of organic accretion for salt marshes ${ }^{1}$ $\left(A_{o}^{c} \approx 3 \mathrm{~mm} / \mathrm{yr}\right)$. This value is consistent with accretion rate data of Mid-Atlantic US salt marshes and falls within a broader range of direct and indirect estimations of organic accretion rates of marshes elsewhere (see Fig. S5 and Supplemental Experimental Procedures). Similarly to the trend of inorganic accretion rates with tidal range (Fig. 4), the predicted threshold $R_{c}$ (Fig. 6) shows a fundamental vulnerability for microtidal marshes $(\delta z<1.5 \mathrm{~m})$ and marshes with relatively low sediment supply (average SSC at the channel bank or marsh edge in the range $C_{0}<20 \mathrm{~g} / \mathrm{m}^{3}$ ).

Self-similarity of marsh fragmentation and power-law distribution of pond size

Because pond size scales with basin size (see Experimental Procedures), the progressive shrinking of tidal basins during marsh fragmentation should lead to a self-similar hierarchy of pond sizes with a Pareto (power-law) distribution ${ }^{54}$. Indeed, we find a power-law distribution of pond areas and a self-similar pattern of marsh loss, in both, our model simulations of marsh fragmentation (shown in Fig. 5A, where pond area is defined as the square of its length) and in rapidly submerging marshes in Blackwater, MD and Louisiana (Fig. 5), where drowning 
begins near the watershed divide and propagates towards the channels ${ }^{41}$.

Interestingly, the exponent of the power-law distribution of the area of simulated ponds changes little with the rate of RSLR above the threshold $R_{c}$, and is very similar to the one obtained for small to medium-size ponds $\left(\lesssim 10^{5} \mathrm{~m}^{2}\right)$ in Blackwater $^{55}$ (Fig. 5B). The exponent $(\sim 1.5)$ is consistent with a simple 'period-doubling' mechanism, where whenever a pond connects to the channel network it creates two new ponds with half the diameter (one quarter of the area) of the 'parent' one.

The size distribution of large ponds in Louisiana ${ }^{56}$ has a larger exponent $(\sim 2.5)$ similar to the one for similar-size ponds in Blackwater (Fig. 5B), which suggests a further scaleinvariant mechanism affecting pond growth.

\section{Discussion}

\section{Vulnerability of microtidal marshes}

Although marsh vulnerability has been traditionally tied to inorganic sediment availability, we find consistently low inorganic accretion in the interior of most microtidal marshes $\left(\lesssim 2.5 \mathrm{~mm} / \mathrm{yr}\right.$, one sixth of existing predictions, e.g. ${ }^{18,19,28}$, see Fig. 4B) regardless of sediment supply. This vulnerability is highest for marshes with tidal ranges $<1 \mathrm{~m}$ (Fig. 4B), where inorganic accretion in the marsh interior is negligible and the threshold RSLR rate seems to be completely determined by organic accretion. This explains the apparent contradiction of Blackwater marshes, where a relatively high suspended sediment concentration in the channels does not prevent drowning $^{32,33}$. With a tidal range $<0.5 \mathrm{~m}$, inorganic accretion is irrelevant for the vast majority of the marsh platform. Thus, it is enough for the local rate of RSLR to be higher than the organic accretion rate to induce widespread drowning (Fig. 6). This indeed seems to be the case in both Blackwater ${ }^{57}$, and in the Mississippi Delta, where the threshold for continuous marsh loss was estimated to be about $3 \mathrm{~mm} / \mathrm{yr}^{58}$, very similar to model prediction for $\delta z<1 \mathrm{~m}$ (Fig. 6). The predicted low inorganic deposition in the marsh interior also agrees with the predominantly organic composition of sediments found in many marshes with tidal range $<1 \mathrm{~m}$ (e.g. Blackwater, $\mathrm{MD}^{57}$; Gulf of Mexico $\left.{ }^{14}\right)$.

While organic accretion is a complex function of several factors, such as plant species, water salinity, flooding frequency, water and soil temperature and composition ${ }^{10,16}$, a meta-analysis of field data reveals organic accretion rates are in the range of $3.0 \pm 2.0 \mathrm{~mm} / \mathrm{yr}$ (Fig.S5 and Supplemental Experimental Procedures), which happens to be in the range of observed RSLR rates. Therefore, it seems we currently are at the tipping point for widespread drowning of global microtidal salt marshes regardless of the local inorganic sediment supply (Fig. 6). Indeed, the model correctly predicts the drowning of Blackwater marshes and marshes in the Mississippi Delta $^{58}$, and also suggests marshes in Venice, the Virginia Eastern Shore (e.g. Phillips Creek) and Plum Island, MA, are particularly vulnerable (Fig. 6).

We thus provide a mechanistic explanation for the widely observed fragility of microtidal marshes ${ }^{11}$ and show this vulnerability is intrinsic and tied to the dominant role of organic accretion. Therefore, factors altering biomass productivity and decomposition, such as eutrophication, elevated $\mathrm{CO}_{2}$ and cli- mate warming $10,11,19,59$, could decide the mid-term response of global microtidal marshes, while measures aimed at increasing sediment delivery could have limited success.

\section{Runaway marsh fragmentation}

The runaway marsh fragmentation induced by the approximate scale invariance of sediment deposition ${ }^{44}$, constitutes a new form of marsh destabilization that transforms the local crossing of the marsh drowning threshold into the onset of eventual widespread marsh loss. This mechanism only requires that connected ponds decrease the size of local drainage basins, regardless of whether they deliver sediment to the marsh platform or not. In the best case scenario depicted in Fig. 5A, connected ponds redistribute inorganic sediment as effective as large channels or mud flats, which is not the case in reality. Any decrease in sediment delivered by connected ponds leads to lower inorganic accretion rates on the surrounding marshes, thereby accelerating marsh drowning.

The scale invariance of sediment deposition, where sediment is deposited closer to the banks in smaller basins, underpinning the runaway marsh fragmentation is consistent with observations that an increased density of artificial channels does not increase overall sedimentation (e.g. Louisiana ${ }^{60}$ ) and in some cases resulted in subsidence (e.g. New England ${ }^{61}$ ). Furthermore, the predicted acceleration of marsh fragmentation with the rate of RSLR (Fig. $5 \mathrm{~A}$ ) is consistent with the rapidly increased rate of historic marsh loss measured in the Mississippi Delta as RSLR accelerated ${ }^{58}$.

The marsh fragmentation mechanism explains the formation of a broad range of pond sizes, and predicts that their size distribution should follow a power-law, in agreement with data from Blackwater marshes (Fig 5B). It also predicts a particular temporal sequence of marsh fragmentation, as large initial ponds eventually lead to smaller ones at a rate increasing with the rate of RSLR relative to the drowning threshold (Fig. 5A), and suggests the area of the larger ponds depends on the initial distribution of tidal basin areas. This multi-scale mechanism complements existing models of pond growth driven by lateral expansion instead of RSLR ${ }^{40,62}$

\section{Conclusions}

We derive a simplified model of sediment transport in the absence of erosion that explains patterns of sediment deposition and marsh vulnerability in a wide variety of conditions. Our model leads to an analytical prediction of inorganic accretion that complements direct measurements of accretion, which necessarily reflect historical rather than future environmental conditions ${ }^{2}$. We predict a new form of marsh destabilization characterized by a progressive fragmentation of the marsh platform, triggered by the drowning of interior marshes. The threshold for this runaway marsh fragmentation is much lower than existing predictions ${ }^{13,63}$ and is largely decoupled from inorganic sediment supply in microtidal environments, which explains the observed fragility of microtidal marshes. Beyond microtidal marshes, the much-lower marsh fragmentation thresholds predicted by our model suggest a re-evaluation of the resiliency of global marshes under current and future scenarios $^{63}$ 
where the bar denotes an average of the form

$$
\bar{C}(x) \equiv \tau(D)^{-1} \int_{-\tau(D) / 2}^{\tau(D) / 2} C\left(x, t^{+}\right) \mathrm{d} t^{+}
$$

where $\tau(D)$ is the rescaled local inundation time and $D(x)=$ $\delta z / 2-Z(x)$ is the local depth.

Because the main effect of a non-flat marsh platform is to change the local inundation time $\tau(D)$, this averaging removes, in a first approximation, the dependence on marsh elevation and thus its solution has the form $\bar{C} \approx \bar{C}(x)$. Therefore, we can use the numerical solution of Eq. 5 for a flat marsh to obtain a correlation between the average sediment flux per unit width $(\overline{Q C})$ and the average suspended sediment concentration $(\bar{C})$. This correlation is expected when transport is dominated by advection instead of diffusion.

Indeed, in the range $x / L \lesssim 0.6$, we find (see Fig. S2)

$$
\overline{Q C}(x) \approx \beta \delta z L T^{-1}(\bar{C}(x)-\bar{C}(L)),
$$

where $\beta=1.5$ is a fitting constant and $\bar{C}(L)$ is defined as an effective sediment concentration at the watershed divide $x=L$. This definition follows from the boundary condition of no average sediment transport across the watershed divide, i.e. $\overline{Q C}(L)=0$. Using Eq. 8, the total mass of sediment deposited on the 1-D marsh during one tidal cycle, $\tau(D) T \int_{0}^{L} w_{f} \bar{C}(x) \mathrm{d} x$, can be approximated by integrating Eq. 6 as $\overline{Q C}(0) \tau(D) T \approx$ $\beta \delta z L \tau(D)(\bar{C}(0)-\bar{C}(L))$.

Substituting the advection approximation (Eq. 8) into Eq. 6 we get an equation for the average suspended sediment concentration

$$
\beta L \partial_{x} \bar{C} \approx-w_{f}^{+} \bar{C}
$$

which has the exponentially decaying solution

$$
\bar{C}(x)=\bar{C}(0) \exp \left(-x / L_{c}\right)
$$

with decay length $L_{c}=\beta L / w_{f}^{+}$, or $L_{c}=\beta L \delta z /\left(T w_{f}\right)$ after substituting $w_{f}^{+}$.

From Eq. 6, the scaling of the decay length has the more general form $L_{c} \propto Q / w_{f}$ (as can be verified using $Q \propto \delta z L / T$ ), which is equivalent to the scaling of the decay or deposition length in unidirectional turbulent suspensions ${ }^{50}: L_{c} \propto H U / w_{f} \propto$ $Q / w_{f}$, where $H$ is the flow depth, $U$ is the (constant) flow velocity and $Q \propto U H$ is the water discharge per unit width.

Finally, the boundary condition $\bar{C}(0)$ in Eq. 10 is obtained numerically from Eq. 5 by averaging $C(0, t)$ over one tidal cycle, which gives (see Fig. S3)

$$
\bar{C}(0)=C_{0} r\left(w_{f}^{+}\right)
$$

with fitting function

$$
r\left(w_{f}^{+}\right)=\left(1+\left(1+w_{f}^{+}\right)^{-1}\right) / 2 .
$$

This function quantifies the average sediment concentration of the ebb flow leaving the marsh platform. Defining $\bar{C}(0) \equiv$ $\left[\bar{C}_{\text {flood }}(0)+\bar{C}_{\text {ebb }}(0)\right] / 2$, substituting Eqs. 11 and 12 , and using our assumption of a constant concentration at the marsh edge during flood $\left(\bar{C}_{\text {flood }}(0)=C_{0}\right)$, we get,

$$
\bar{C}_{\mathrm{ebb}}(0)=C_{0}\left(2 r\left(w_{f}^{+}\right)-1\right)=C_{0} /\left(1+w_{f}^{+}\right) .
$$

For small tidal ranges, the rescaled falling velocity diverges, $\bar{C}_{\text {ebb }}(0) \rightarrow 0$ and most of the sediment is deposited on the marsh. For large tidal ranges, the opposite is true, $w_{f}^{+} \rightarrow 0$ and $\bar{C}_{\text {ebb }}(0) \rightarrow C_{0}$, i.e. most of the sediment leaves the march. 


\section{Inorganic accretion rate}

In the absence of erosion, the net inorganic accretion rate averaged over a tidal cycle is defined as the volume of inorganic sediments suspended in the water column that settles on the marsh surface per unit area and unit time, and can be approximated as $A_{i}(x, D)=\rho_{i}^{-1} w_{f} \tau(D) \bar{C}(x)$, where $\rho_{i}$ is the long-term averaged density of deposited sediments ${ }^{1}$ and $\tau(D) \approx \pi^{-1} \arccos (1-2 D / \delta z)$ is the average rescaled inundation time. Using Eq. 10, $A_{i}(x, D)$ can be approximated as

$$
A_{i}(x, D) \approx \rho_{i}^{-1} C_{0} r\left(w_{f}^{+}\right) w_{f} \tau(D) \exp \left(-x / L_{c}\right) .
$$

In general, sediment transport properties $\left(C_{0}, L_{c}, D, \tau(D)\right.$, etc.) change with tidal range. However, in what follow (as within the main-text) we assume the average inorganic accretion rate can be simply calculated by Eq. 14 evaluated at a mean tidal range, denoted as $\delta z$ for simplicity. When comparing to field data, $\delta z$ is the mean over the measurement period, otherwise we use a representative value.

\section{Simplified one-dimensional model of marsh dynamics} In order to calculate the response of the marsh/mud elevation, $Z(x, t)=\delta z / 2-D(x, t)$, to a rate $R$ of RSLR, we propose a minimal model for the total accretion rate $\partial_{t} Z$ as function of the local elevation that describes: (i) marsh drowning, (ii) the formation of isolated ponds and (iii) the changes in the accretion rates once isolated ponds connect to the channel network. This model is used to generate the simulations shown in Fig. 5A.

We assume that above a critical elevation $Z_{c}$ for marsh recovery (see "Model approach" in the main text), marshes are widespread and both inorganic and organic accretion contributes to $\partial_{t} Z$. In that case, $\partial_{t} Z=A_{i}(x, Z, t)+A_{o}(D)-R$, where $A_{o}(D)$ is the depth-dependent organic accretion rate (by definition $D=\delta z / 2-Z$ ). We assume that for elevations below $Z_{c}$ but above an arbitrary lower elevation $Z_{t}$, marshes drown $\left(A_{o}=0\right)$ and form isolated ponds with no net inorganic accretion $\left(A_{i}=0\right)$. Thus, the average deepening rate of an isolate pond equals the rate of RSLR: $\partial_{t} Z=-R$. Finally, when the pond elevation is below $Z_{t}$, we assume ponds connect to the channel network and reach an equilibrium depth slightly lower than $Z_{t}$, and thus $\partial_{t} Z=0$.

The minimal marsh model has the form:

$$
\partial_{t} Z= \begin{cases}A_{i}(x, Z, t)+A_{o}(D)-R & \text { for } Z>Z_{c} \\ -R & \text { for } Z_{t}<Z \leq Z_{c} \\ 0 & \text { for } Z \leq Z_{t}\end{cases}
$$

Since we are primarily interested in drowning marshes, for which $R>\max \left\{A_{o}\right\}$ and thus are closer to the critical elevation $Z_{c}$, we assume for simplicity a constant accretion rate $A_{o}$ in the range $A_{o}^{c} \leq A_{o} \leq \max \left\{A_{o}\right\}$, where $A_{o}^{c}=A_{o}\left(D_{c}\right)$ is the organic accretion rate at the critical depth $\left(D_{c}=\delta z / 2-Z_{c}\right)$.

The inorganic accretion rate $A_{i}(x, Z, t)$ is given by Eq. 14 and can be written in terms of the critical accretion rate in the marsh interior, $A_{i}^{c}(L)=A_{i}\left(L, D_{c}\right)$, as:

$$
A_{i}(x, Z, t)=A_{i}^{c}(L) \frac{\tau(Z)}{\tau\left(Z_{c}\right)} \exp \left(\frac{1-\ell(x, t)}{\ell_{c}}\right),
$$

where $\tau(Z)=\pi^{-1} \arccos (2 Z / \delta z)$ is the rescaled inundation time at elevation $Z, \ell_{c}=\beta / w_{f}^{+}$is the rescaled decay length $\ell_{c}=L_{c} / L$ and the function $\ell(x, t) \in[0,1]$ is defined as the distance from the edge of a channel (or connected pond) rescaled such that $\ell=1$ at the corresponding watershed divide (e.g. $\ell(x)=x / L$ if the marsh edge is at $x=0$ and the watershed divide at $x=L$ ).

A further simplification is obtained by approximating $\pi^{-1} \arccos (x)$ by $(1-x) / 2$ in the rescaled inundation time $\tau$, which gives

$$
\tau(Z)=\frac{1}{2}-\frac{Z(x, t)}{\delta z}
$$

Using $Z_{c} / \delta z=0.15$ as the critical elevation for marshes (corresponding to $D_{c}=0.35 \delta z$, see Fig. 1) we get $\tau\left(Z_{c}\right)=0.35$.

The function $\ell(x, t)$ in Eq. 16 generalizes the concept of the distance $x$ to the marsh edge to account for the formation of new connected ponds. We assume that connected ponds change the geometry of the drainage basin and become a new source of both tidal water and inorganic sediment with concentration $C_{0}$. As ponds get deeper than $Z_{t}$ and connect to the channel network, we update the term $\ell(x, t)$ to reflect the positions $x_{j}$ of the new marsh edges (defined by the condition $Z\left(x_{j}\right)=Z_{t}$ ), and corresponding watershed divides (defined as the midpoint between neighboring channels or connected ponds.)

For the numerical integration of Eqs. 15, 16 and 17, rates are rescaled by the drowning threshold $R_{c}=A_{o}+A_{i}^{c}(L)$, lengths are rescaled by the initial domain size $L_{0}$, elevations are rescaled by tidal range $\delta z$ and times are rescaled by $\delta z / R_{c}$. Since $A_{i}^{c}(L)=R_{c}-A_{o}$ by definition, the model has five dimensionless parameters: $R / R_{c}, A_{o} / R_{c}, \ell_{c}, Z_{c} / \delta z$ and $Z_{t} / \delta z$.

For the simulations shown in Fig. $5 \mathrm{~A}$, we choose values representative of a microtidal marsh with moderate sediment supply: $\delta z=1 \mathrm{~m}$ and $C_{0}=50 \mathrm{~g} / \mathrm{m}^{3}$, with $A_{o}=3 \mathrm{~mm} / \mathrm{yr}, w_{f}=$ $10^{-4} \mathrm{~m} / \mathrm{s}$ and $T=12.5 \mathrm{~h}$. We thus get $A_{o} / R_{c}=0.78$ and $\ell_{c}=1 / 3$. We use a rescaled critical elevation $Z_{c} / \delta z=0.15$ consistent with field data (Fig. 1B), and assume ponds with a depth around MSL connect to channels, thus $Z_{t} / \delta z=0$. We change the rescaled RSLR rates $R / R_{c}$ in the range $0.8-5$. The initial condition is a marsh platform of rescaled elevation $Z / \delta z=0.4$ and unit rescaled length, limited by tidal channels at both sides. For the pond size distributions shown in Fig. 5B, we choose a $10 \mathrm{~km}$ domain size.

\section{Scaling of the equilibrium pond size $L_{p}$}

The scale invariance of spatial sediment deposition patterns leads to a similar scale invariance in the size, or diameter $L_{p}$, of the resulting ponds. Assuming the edge of the pond, a distance $x_{p}=L-L_{p} / 2$ from the channel bank, is at equilibrium with RSLR at the critical depth $D_{c}$, then $R=A_{o}^{c}+A_{i}^{c}\left(x_{p}\right)$ (Eq. 15). Substituting Eq. 16 with $Z\left(x_{p}\right)=Z_{c}$ and rescaled position of the pond edge $\ell\left(x_{p}\right)=x_{p} / L=1-L_{p} /(2 L)$, and using the definition of the drowning threshold $R_{c}=A_{o}^{c}+A_{i}^{c}(L)$, the rescaled equilibrium pond size is

$$
\frac{L_{p}}{L}=2 \ell_{c} \ln \left(\frac{R-A_{o}^{c}}{R_{c}-A_{o}^{c}}\right),
$$

where, $\ell_{c}=\beta / w_{f}^{+}=\beta \delta z /\left(T w_{f}\right)$ is the rescaled sediment concentration decay length.

The rescaled equilibrium pond size (Eq.18) has two limits: no permanent ponds $\left(L_{p}=0\right)$ for $R \leq R_{c}$, and no marshes $\left(L_{p}=2 L\right)$ above the highest drowning threshold at marsh edge, $R \geq A_{o}^{c}+A_{i}^{c}(0)=A_{o}^{c}+\left(R_{c}-A_{o}^{c}\right) \exp \left(1 / \ell_{c}\right)($ Fig. 5A). Note that 
this pond size is a minimum value as we assume no lateral pond erosion besides marsh drowning.

\section{Analysis and interpretation of inorganic accretion data} To only test the dependence on the distance to channel, reported accretion rates $A_{i}$ for Phillips Creek (Fig. 3D) were depth-corrected to eliminate the scaling with the flooding frequency: $A_{i}^{*}=A_{i} \tau(\bar{D}) / \tau(D)$, where $\tau(D)=$ $\pi^{-1} \arccos (1-2 D / \delta z)$ is the approximated rescaled inundation time and $\bar{D}$ is the mean marsh depth. We couldn't perform a similar correction for Norfolk (Fig. 3E) because lack of detailed elevation data. However, the fact this marsh is relatively young and hasn't reached a steady state elevation yet suggests the noticeable exponential decay in both the 5-year average accretion rates and the values during individual tides is mainly due to the spatial gradient of sediment distribution ${ }^{21}$. For the Bay of Fundy, there is no obvious trend in accretion rates as they were poorly correlated with both marsh elevation (for the relevant range above $5.2 \mathrm{~m}$ ) and distance to channel (Fig. 3F). However, this is consistent with our prediction for very large tidal ranges (Eq. 2).

\section{Acknowledgements}

We acknowledge Lennert Schepers for kindly providing some of the pond area data. This work was funded by the National Science Foundation Coastal SEES (\#1426981), GLD (\#1529245), CAREER (\#1654374), and LTER (\#1237733) programs. O.D.V. acknowledges the support of the Texas A\&M Engineering Experiment Station (TEES).

\section{Author Contributions}

Conceptualization, O.D.V, E.R.H. and M.L.K.; Methodology, O.D.V; Software, O.D.V; Investigation, O.D.V; Writing-Original Draft, O.D.V, E.R.H. and M.L.K.; Writing-Review \& Editing, O.D.V, E.R.H. and M.L.K.; Validation, O.D.V., D.J.C. and J.D.H.; Funding Acquisition, M.L.K.

\section{Declaration of Interests}

The authors declare no competing interests.

\section{References}

1. Morris, J. T., Barber, D. C., Callaway, J. C., Chambers, R., Hagen, S. C., Hopkinson, C. S., Johnson, B. J., Megonigal, P., Neubauer, S. C., Troxler, T. \& Wigand, C. (2016). Contributions of organic and inorganic matter to sediment volume and accretion in tidal wetlands at steady state: Sediment bulk density and ignition loss. Earth's Futur. 4, 110-121, 10.1002/2015EF000334.

2. Kirwan, M. L., Temmerman, S., Skeehan, E. E., Guntenspergen, G. R. \& Fagherazzi, S. (2016). Overestimation of marsh vulnerability to sea level rise. Nat. Clim. Chang. 6, 253-260, 10.1038/nclimate2909.

3. Marani, M., D’Alpaos, A., Lanzoni, S., Carniello, L. \& Rinaldo, A. (2007). Biologically-controlled multiple equilibria of tidal landforms and the fate of the Venice lagoon. Geophys. Res. Lett. 34, 10.1029/2007GL030178.
4. Fagherazzi, S., Kirwan, M. L., Mudd, S. M., Guntenspergen, G. R., Temmerman, S., Rybczyk, J. M., Reyes, E., Craft, C. \& Clough, J. (2012). Numerical models of salt marsh evolution: Ecological, geormorphic, and climatic factors. Rev. Geophys. 1-28, 10.1029/2011RG000359.

5. Kolker, A. S., Kirwan, M. L., Goodbred, S. L. \& Cochran, J. K. (2010). Global climate changes recorded in coastal wetland sediments: Empirical observations linked to theoretical predictions. Geophys. Res. Lett. 37, 10.1029/ 2010 GL043874.

6. Hill, T. D. \& Anisfeld, S. C. (2015). Coastal wetland response to sea level rise in Connecticut and New York. Estuarine, Coast. Shelf Sci. 163, 185-193, 10.1016/j.ecss. 2015.06.004.

7. Alizad, K., Hagen, S. C., Morris, J. T., Medeiros, S. C. Bilskie, M. V. \& Weishampel, J. F. (2016). Coastal wetland response to sea-level rise in a fluvial estuarine system. Earth's Futur. 4, 483-497, 10.1002/2016EF000385.

8. Alizad, K., Hagen, S. C., Medeiros, S. C., Bilskie, M. V., Morris, J. T., Balthis, L. \& Buckel, C. A. (2018). Dynamic responses and implications to coastal wetlands and the surrounding regions under sea level rise. PLOS ONE 13, e0205176, 10.1371/journal.pone.0205176.

9. Day, J., Ibáñez, C., Scarton, F., Pont, D., Hensel, P., Day, J. \& Lane, R. (2011). Sustainability of Mediterranean Deltaic and Lagoon Wetlands with Sea-Level Rise: The Importance of River Input. Estuaries Coasts 34, 483-493, 10.1007/s12237-011-9390-x.

10. Kirwan, M. L. \& Megonigal, J. P. (2013). Tidal wetland stability in the face of human impacts and sea-level rise. Nature 504, 53-60, 10.1038/nature12856.

11. Kearney, M. S. (2016). Microtidal Marshes: Can These Widespread and Fragile Marshes Survive Increasing Climate-Sea Level Variability and Human Action? J. Coast. Res. 32, 686, 10.2112/JCOASTRES-D-15-00069.1.

12. D’Alpaos, A., Mudd, S. M. \& Carniello, L. (2011). Dynamic response of marshes to perturbations in suspended sediment concentrations and rates of relative sea level rise. J. Geophys. Res. Earth Surf. 116, 10.1029/2011JF002093.

13. Kirwan, M. L., Guntenspergen, G. R., D'Alpaos, A., Morris, J. T., Mudd, S. M. \& Temmerman, S. (2010). Limits on the adaptability of coastal marshes to rising sea level. Geophys. Res. Lett. 37, n/a-n/a, 10.1029/2010GL045489.

14. Turner, R. E., Swenson, E. M. \& Milan, C. S. Organic and Inorganic Contributions to Vertical Accretion in Salt Marsh Sediments. In Concepts and Controversies in Tidal Marsh Ecology, 583-595, 10.1007/0-306-47534-027 (Springer, Dordrecht, 2002).

15. Nyman, J. A., Walters, R. J., Delaune, R. D. \& Patrick, W. H. (2006). Marsh vertical accretion via vegetative growth. Estuarine, Coast. Shelf Sci. 69, 370-380, 10.1016/ j.ecss.2006.05.041.

16. Neubauer, S. C. (2008). Contributions of mineral and organic components to tidal freshwater marsh accretion. Estuarine, Coast. Shelf Sci. 78, 78-88, 10.1016/j.ecss.2007. 11.011 .

17. Kirwan, M. L. \& Guntenspergen, G. R. (2012). Feedbacks between inundation, root production, and shoot growth 
in a rapidly submerging brackish marsh. J. Ecol. 100, 764-770, 10.1111/j.1365-2745.2012.01957.x.

18. D'Alpaos, A. (2011). The mutual influence of biotic and abiotic components on the long-term ecomorphodynamic evolution of salt-marsh ecosystems. Geomorphology 126, 269-278, 10.1016/j.geomorph.2010.04.027.

19. Ratliff, K. M., Braswell, A. E. \& Marani, M. (2015). Spatial response of coastal marshes to increased atmospheric $\mathrm{CO}_{2}$. Proc. Natl. Acad. Sci. 201516286, 10.1073/pnas. 1516286112

20. D'Alpaos, A. \& Marani, M. (2016). Reading the signatures of biologic-geomorphic feedbacks in salt-marsh landscapes. Adv. Water Resour. 93, Part B, 265-275, 10.1016/j.advwatres.2015.09.004.

21. French, J. R. \& Spencer, T. (1993). Dynamics of sedimentation in a tide-dominated backbarrier salt marsh, Norfolk, UK. Mar. Geol. 110, 315-331.

22. Christiansen, T., Wiberg, P. \& Milligan, T. (2000). Flow and Sediment Transport on a Tidal Salt Marsh Surface. Estuarine, Coast. Shelf Sci. 50, 315-331, 10.1006/ecss. 2000.0548 .

23. Temmerman, S., Govers, G., Wartel, S. \& Meire, P. (2003). Spatial and temporal factors controlling short-term sedimentation in a salt and freshwater tidal marsh, Scheldt estuary, Belgium, SW Netherlands. Earth Surf. Process. Landforms 28, 739-755.

24. Reed, D. J. (1995). The response of coastal marshes to sea-level rise: Survival or submergence? Earth Surf. Process. Landforms 20, 39-48, 10.1002/esp.3290200105.

25. Fagherazzi, S., Wiberg, P. L., Temmerman, S., Struyf, E., Zhao, Y. \& Raymond, P. A. (2013). Fluxes of water, sediments, and biogeochemical compounds in salt marshes. Ecol. Process. 2, 3, 10.1186/2192-1709-2-3.

26. Temmerman, S., Bouma, T. J., Govers, G., Wang, Z. B., De Vries, M. B. \& Herman, P. M. J. (2005). Impact of vegetation on flow routing and sedimentation patterns: Three-dimensional modeling for a tidal marsh. J. Geophys. Res. Earth Surf. 110, n/a-n/a, 10.1029/2005JF000301.

27. D’Alpaos, A., Lanzoni, S., Marani, M. \& Rinaldo, A. (2007). Landscape evolution in tidal embayments: Modeling the interplay of erosion, sedimentation, and vegetation dynamics. J. Geophys. Res. Earth Surf. 112, F01008, 10.1029/2006JF000537.

28. Da Lio Cristina, D’Alpaos Andrea \& Marani Marco (2013). The secret gardener: vegetation and the emergence of biogeomorphic patterns in tidal environments. Philos. Transactions Royal Soc. A: Math. Phys. Eng. Sci. 371, 20120367, 10.1098/rsta.2012.0367.

29. Belliard, J. P., Di Marco, N., Carniello, L. \& Toffolon, M. (2016). Sediment and vegetation spatial dynamics facing sea-level rise in microtidal salt marshes: Insights from an ecogeomorphic model. Adv. Water Resour. 93, 249-264, 10.1016/j.advwatres.2015.11.020.

30. Mudd, S. M., D’Alpaos, A. \& Morris, J. T. (2010). How does vegetation affect sedimentation on tidal marshes? Investigating particle capture and hydrodynamic controls on biologically mediated sedimentation. J. Geophys. Res. 115, 10.1029/2009JF001566.
31. Roner, M., D’Alpaos, A., Ghinassi, M., Marani, M., Silvestri, S., Franceschinis, E. \& Realdon, N. (2016). Spatial variation of salt-marsh organic and inorganic deposition and organic carbon accumulation: Inferences from the Venice lagoon, Italy. Adv. Water Resour. 93, Part B, 276287, 10.1016/j.advwatres.2015.11.011.

32. Ganju, N. K., Kirwan, M. L., Dickhudt, P. J., Guntenspergen, G. R., Cahoon, D. R. \& Kroeger, K. D. (2015). Sediment transport-based metrics of wetland stability: Sediment Metrics of Wetland Stability. Geophys. Res. Lett. 42, 7992-8000, 10.1002/2015GL065980.

33. Ganju, N. K., Defne, Z., Kirwan, M. L., Fagherazzi, S., D'Alpaos, A. \& Carniello, L. (2017). Spatially integrative metrics reveal hidden vulnerability of microtidal salt marshes. Nat. Commun. 8, 10.1038/ncomms 14156.

34. Christiansen, T. Sediment Deposition on a Tidal Salt Marsh. Ph.D. thesis, University of Virginia, Charlottesville (1998).

35. Coleman, D. J. \& Kirwan, M. L. (2019). The effect of a small vegetation dieback event on salt marsh sediment transport. Earth Surf. Process. Landforms 44, 944-952, 10.1002/esp.4547.

36. Morris, J. T., Sundareshwar, P. V., Nietch, C. T., Kjerfve, B. \& Cahoon, D. R. (2002). Responses of coastal wetlands to rising sea level. Ecology 83, 2869-2877.

37. French, J. (2006). Tidal marsh sedimentation and resilience to environmental change: Exploratory modelling of tidal, sea-level and sediment supply forcing in predominantly allochthonous systems. Mar. Geol. 235, 119-136, 10.1016/j.margeo.2006.10.009.

38. Carniello, L., Defina, A. \& D’Alpaos, L. (2012). Modeling sand-mud transport induced by tidal currents and wind waves in shallow microtidal basins: Application to the Venice Lagoon (Italy). Estuarine, Coast. Shelf Sci. 102103, 105-115, 10.1016/j.ecss.2012.03.016.

39. Marani, M., Lio, C. D. \& D'Alpaos, A. (2013). Vegetation engineers marsh morphology through multiple competing stable states. Proc. Natl. Acad. Sci. 110, 3259-3263, 10.1073/pnas.1218327110.

40. Mariotti, G. (2016). Revisiting salt marsh resilience to sea level rise: Are ponds responsible for permanent land loss? J. Geophys. Res. Earth Surf. 121, 1391-1407, 10.1002/2016JF003900.

41. Schepers, L., Kirwan, M., Guntenspergen, G. \& Temmerman, S. (2017). Spatio-temporal development of vegetation die-off in a submerging coastal marsh: Spatiotemporal marsh die-off. Limnol. Oceanogr. 62, 137-150, 10.1002/lno.10381.

42. Wilson, C. A., Hughes, Z. J., FitzGerald, D. M., Hopkinson, C. S., Valentine, V. \& Kolker, A. S. (2014). Saltmarsh pool and tidal creek morphodynamics: Dynamic equilibrium of northern latitude saltmarshes? Geomorphology 213, 99-115, 10.1016/j.geomorph.2014.01.002.

43. van Belzen, J., van de Koppel, J., Kirwan, M. L., van der Wal, D., Herman, P. M. J., Dakos, V., Kéfi, S., Scheffer, M., Guntenspergen, G. R. \& Bouma, T. J. (2017). Vegetation recovery in tidal marshes reveals critical slowing down under increased inundation. Nat. Commun. 8, 15811, 10.1038 /ncomms 15811 . 
44. Rinaldo, A., Fagherazzi, S., Lanzoni, S., Marani, M. \& Dietrich, W. E. (1999). Tidal networks 2. Watershed delineation and comparative network morphology. Water Resour. Res. 35, 3905-3917.

45. Belliard, J.-P., Toffolon, M., Carniello, L. \& D’Alpaos, A. (2015). An ecogeomorphic model of tidal channel initiation and elaboration in progressive marsh accretional contexts. J. Geophys. Res. Earth Surf. 120, 1040-1064, 10.1002/ 2015JF003445.

46. Wang, C. \& Temmerman, S. (2013). Does biogeomorphic feedback lead to abrupt shifts between alternative landscape states?: An empirical study on intertidal flats and marshes. J. Geophys. Res. Earth Surf. 118, 229-240, 10.1029/2012JF002474.

47. Defina, a., Carniello, L., Fagherazzi, S. \& D’Alpaos, L. (2007). Self-organization of shallow basins in tidal flats and salt marshes. J. Geophys. Res. 112, F03001-F03001, 10.1029/2006JF000550.

48. Fagherazzi, S., Carniello, L., D’Alpaos, L. \& Defina, A. (2006). Critical bifurcation of shallow microtidal landforms in tidal flats and salt marshes. Proc. Natl. Acad. Sci. United States Am. 103, 8337-41, 10.1073/pnas.0508379103.

49. Wang, C., Schepers, L., Kirwan, M. L., Belluco, E., D'Alpaos, A., Wang, Q., Yin, S. \& Temmerman, S. (2021). Different coastal marsh sites reflect similar topographic conditions under which bare patches and vegetation recovery occur. Earth Surf. Dyn. 9, 71-88, 10.5194/esurf-9-71-2021.

50. Claudin, P., Charru, F. \& Andreotti, B. (2011). Transport relaxation time and length scales in turbulent suspensions. J. Fluid Mech. 671, 491-506, 10.1017/S0022112010005823.

51. Coleman, D. J., Ganju, N. K. \& Kirwan, M. L. (2020). Sediment delivery to a tidal marsh platform is minimized by source decoupling and flux convergence. J. Geophys. Res. Surf. (in press) 10.1029/2020JF005558.

52. van Proosdij, D., Davidson-Arnott, R. G. \& Ollerhead, J. (2006). Controls on spatial patterns of sediment deposition across a macro-tidal salt marsh surface over single tidal cycles. Estuarine, Coast. Shelf Sci. 69, 64-86, 10.1016/j.ecss.2006.04.022.

53. Mariotti, G., Kearney, W. \& Fagherazzi, S. (2016). Soil creep in salt marshes. Geology G37708.1, 10.1130/ G37708.1.

54. Newman, M. (2005). Power laws, pareto distributions and zipf's law. Contemp. Phys. 46, 323-351, 10.1080/ 00107510500052444.

55. Himmelstein, J. D. Mechanisms of Pond Expansion on the Saltmarshes of the Blackwater National Wildlife Refuge, Maryland. Master's thesis, The College of William and Mary (2018).

56. Ortiz, A. C., Roy, S. \& Edmonds, D. A. (2017). Land loss by pond expansion on the mississippi river delta plain. Geophys. Res. Lett. 44, 3635-3642, 10.1002/2017GL073079.

57. Stevenson, J. C., Kearney, M. S. \& Pendleton, E. C. (1985). Sedimentation and erosion in a Chesapeake Bay brackish marsh system. Mar. Geol. 67, 213-235.

58. Törnqvist, T. E., Jankowski, K. L., Li, Y.-X. \& González, J. L. (2020). Tipping points of Mississippi Delta marshes due to accelerated sea-level rise. Sci. Adv. 6, eaaz5512, 10.1126/sciadv.aaz5512.

59. Reef, R., Spencer, T., Möller, I., Lovelock, C. E., Christie, E. K., Mclvor, A. L., Evans, B. R. \& Tempest, J. A. (2017). The effects of elevated $\mathrm{CO}_{2}$ and eutrophication on surface elevation gain in a European salt marsh. Glob. Chang. Biol. 23, 881-890, 10.1111/gcb.13396.

60. DeLaune, R. D., Whitcomb, J. H., Patrick, W. H., Pardue, J. H. \& Pezeshki, S. R. (1989). Accretion and canal impacts in a rapidly subsiding wetland. I. $137 \mathrm{Cs}$ and 210 $\mathrm{Pb}$ techniques. Estuaries Coasts 12, 247-259.

61. Burdick, D. M., Moore, G. E., Adamowicz, S. C., Wilson, G. M. \& Peter, C. R. (2019). Mitigating the Legacy Effects of Ditching in a New England Salt Marsh. Estuaries Coasts 10.1007/s12237-019-00656-5.

62. Mariotti, G. \& Fagherazzi, S. (2013). Critical width of tidal flats triggers marsh collapse in the absence of sea-level rise. Proc. Natl. Acad. Sci. 110, 5353-5356, 10.1073/pnas. 1219600110.

63. Schuerch, M., Spencer, T., Temmerman, S., Kirwan, M. L., Wolff, C., Lincke, D., McOwen, C. J., Pickering, M. D., Reef, R., Vafeidis, A. T., Hinkel, J., Nicholls, R. J. \& Brown, S. (2018). Future response of global coastal wetlands to sea-level rise. Nature 561, 231-234, 10.1038/s41586-018-0476-5.

64. Temmerman, S., Govers, G., Wartel, S. \& Meire, P. (2004). Modelling estuarine variations in tidal marsh sedimentation: response to changing sea level and suspended sediment concentrations. Mar. Geol. 212, 1-19, 10.1016/j.margeo.2004.10.021. 


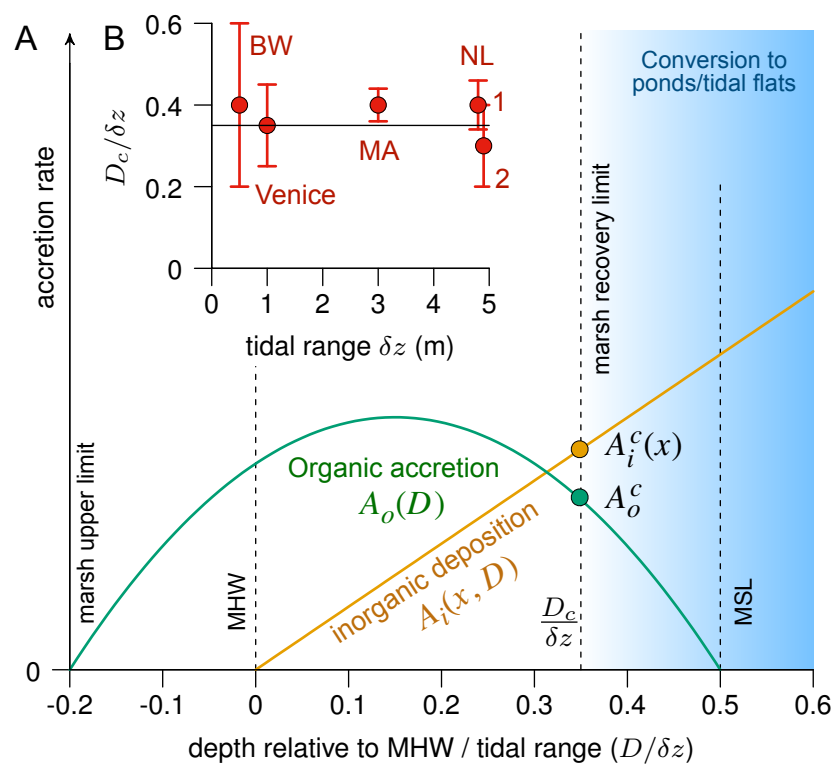

Figure 1. Critical depth for marsh recovery. (A) Sketch of the organic $\left(A_{o}\right)$ and inorganic $\left(A_{i}\right)$ accretion rates on a marsh platform as function of the local water depth $(D)$ relative to mean high water level (MHW) and rescaled by tidal range $\delta z$. Accretion rates $\left(A_{i}^{c}\right.$ and $\left.A_{o}^{c}\right)$ at the critical depth for marsh recovery $\left(D_{c}\right)$ determine the marsh response to sea level rise, where $A_{i}^{c}(x)$ is in general function of the distance $x$ to sediment sources. (B) Estimated values for the rescaled critical depth $\left(D_{c} / \delta z\right)$ at different locations suggested by field data: Blackwater, MD $(\mathrm{BW})^{49}$; Plum Island, MA (MA) ${ }^{42}$; Venice, Italy (general ${ }^{47,48}$ and for San Felice marshes ${ }^{49}$ ); Hallegat and Paulina marshes, NL (NL 1) ${ }^{43}$; and Western Scheldt estuary, NL (NL 2) ${ }^{46}$ (see Table S1 for details). 


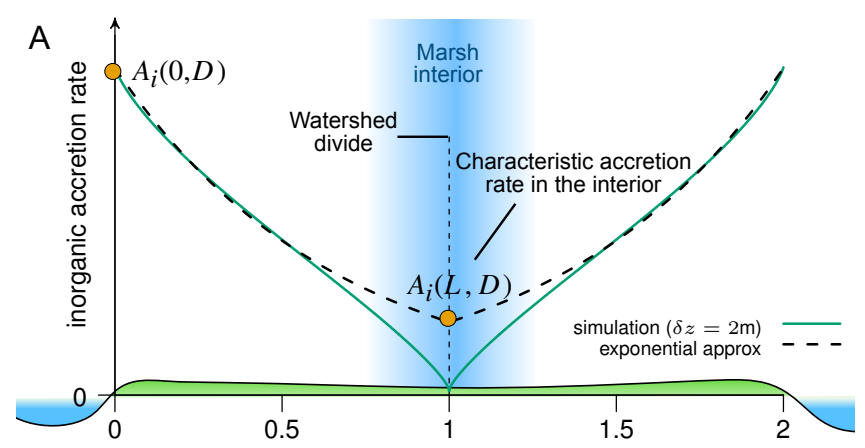

rescaled distance to left channel $(x / L)$

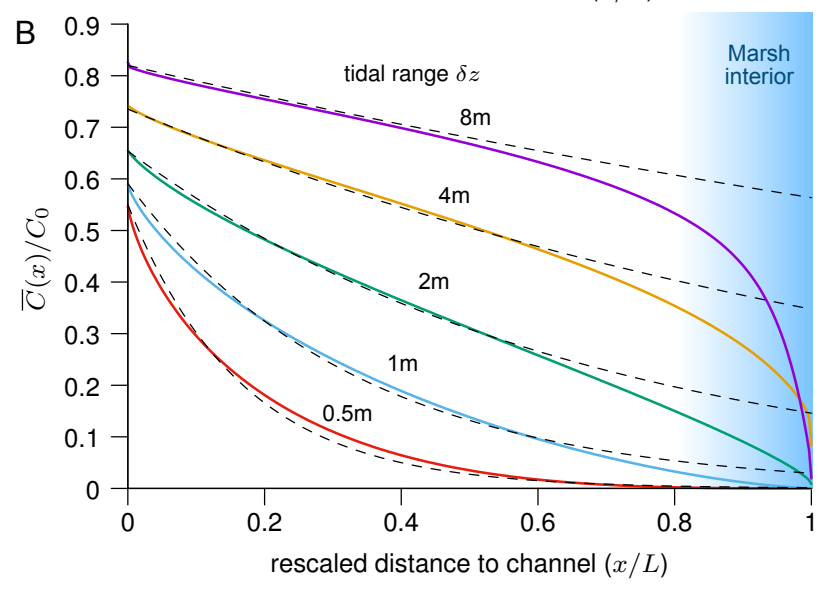

Figure 2. Spatial decay of sediment concentration and scaling with tidal range. Simulation and exponential approximation of the decay of the average sediment concentration $\bar{C}$ with the rescaled distance from channel $x / L$, where $L$ is the length of the drainage basin. For illustration purposes we show in (A) the inorganic accretion rate for a constant marsh depth $D$-such that $A_{i}(x, D) \propto \bar{C}(x)$ - where $A_{i}(0, D)$ is the accretion rate at the marsh edge and $A_{i}(L, D)$ is the characteristic accretion rate in the marsh interior. (B) Rescaled $\bar{C} / C_{0}$ simulated for simplicity for constant marsh depth and varying tidal range $\delta z$ (solid lines). The effective sediment falling velocity is $w_{f}=10^{-4} \mathrm{~m} / \mathrm{s}$ and the tidal period is $T=12.5 \mathrm{~h}$. Dashed lines show the exponential approximation $\bar{C}(x)=\bar{C}(0) e^{-x / L_{c}}$ with $L_{c}$ given by Eq. 2 . 

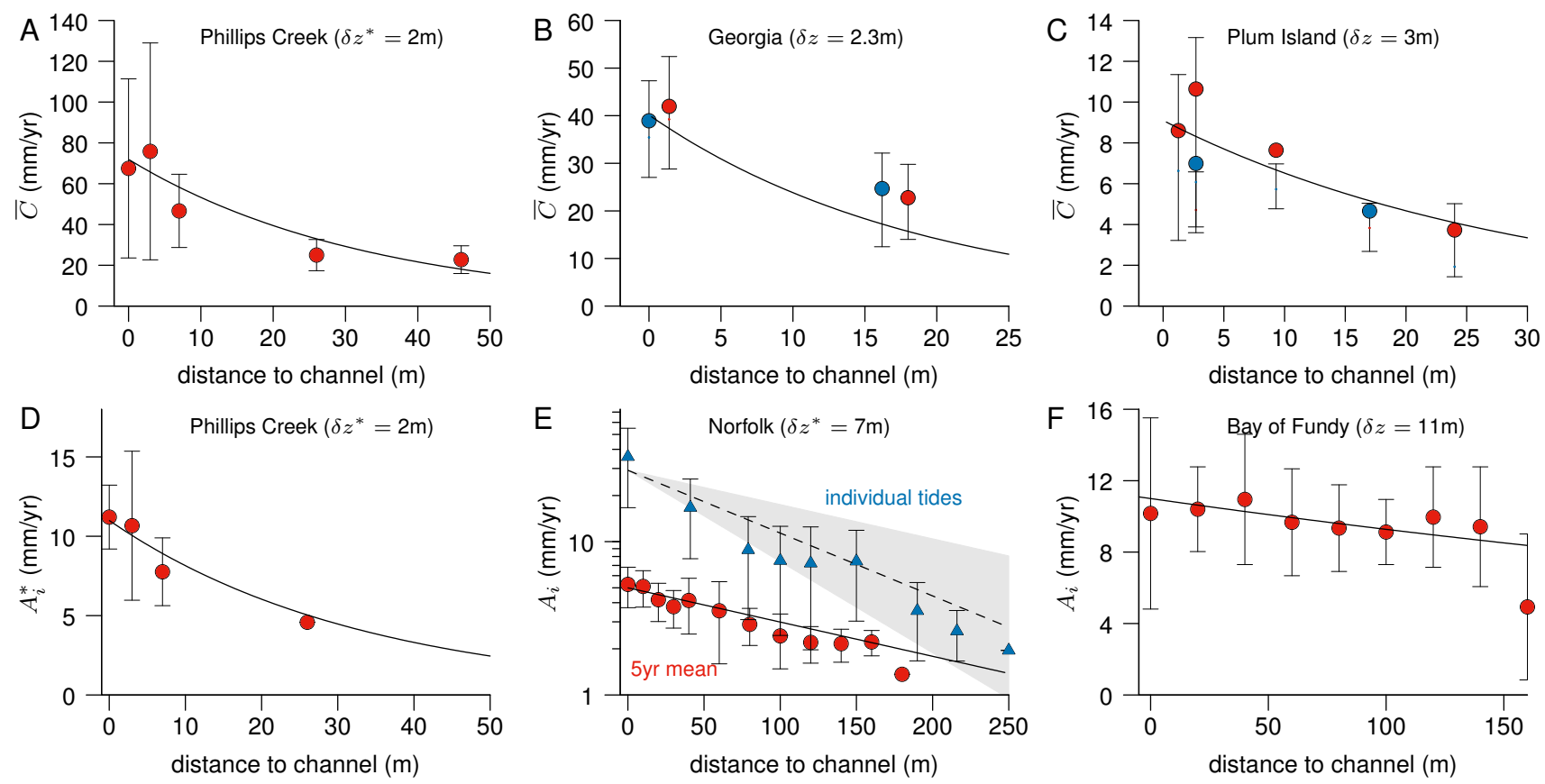

Figure 3. Validation of the exponential decay of sediment concentration and inorganic accretion. Proposed exponential decay (lines) compared to measurements of averaged sediment concentration $\bar{C}\left(\mathrm{~A}^{34}, \mathrm{~B}^{35}\right.$ and $\left.\mathrm{C}^{51}\right)$ and inorganic accretion rate $A_{i}\left(\mathrm{D}^{34}, \mathrm{E}^{21}\right.$ and $\left.\mathrm{F}^{52}\right)$ (symbols). $A_{i}^{*}$ is the depth-corrected accretion rate (see Experimental Procedures for more information). The scaling of the decay length is obtained from the model as $L_{c}=1.5 L \delta z /\left(T w_{f}\right)$ (e.g. Eq. 2), where $\delta z$ is the tidal range, $T$ is tidal period and $w_{f}$ is the effective sediment falling velocity. In all cases $L$ is taken as the maximum distance to a channel reported in the data, $\delta z\left(\delta z^{*}\right)$ is the reported tidal range (average/typical tidal range during the measurement period), and we use the generic value $w_{f}=10^{-4} \mathrm{~m} / \mathrm{s}^{3,22,64}$ unless stated otherwise. Values of $\bar{C}(0)$ and $A_{i}(0)$ were fitted to data. Mass accretion rate data was converted to volume accretion rate using an effective density of inorganic sediments deposited in the marsh $\rho_{i} \approx 2 \mathrm{~g} / \mathrm{cm}^{31}$. All symbols correspond to the average of reported values. Error bars in $(A),(D)$ and $(F)$ represent the standard deviation of the measurements, whereas in $(B)$ and $(C)$ represent the $25^{\text {th }}$ and $75^{\text {th }}$ percentiles. Error bars in $(E)$ represent either the standard deviation (5-year mean data, circles) or the range (individual-tide data, triangles) of reported data. Colors in (B) and (C) correspond to different measurement periods. In (A), $\bar{C}$ is calculated as the mean of the reported maximum concentrations measured during flood and ebb. In (E), we assume $w_{f}=3 \times 10^{-4} \mathrm{~m} / \mathrm{s}$, which is the lowest value of the reported range of settling velocities $\left(w_{f}=3-8 \times 10^{-4} \mathrm{~m} / \mathrm{s}\right)$ to fit the long-term measurements (solid line), whereas we use the average value, $w_{f}=(5.5 \pm 2.5) \times 10^{-4} \mathrm{~m} / \mathrm{s}$, for measurements during single tides (dashed line and shaded area). In both cases the effective tidal range $\delta z^{*}=7 \mathrm{~m}$ is the average of the reported range $6-8 \mathrm{~m}^{21}$. 

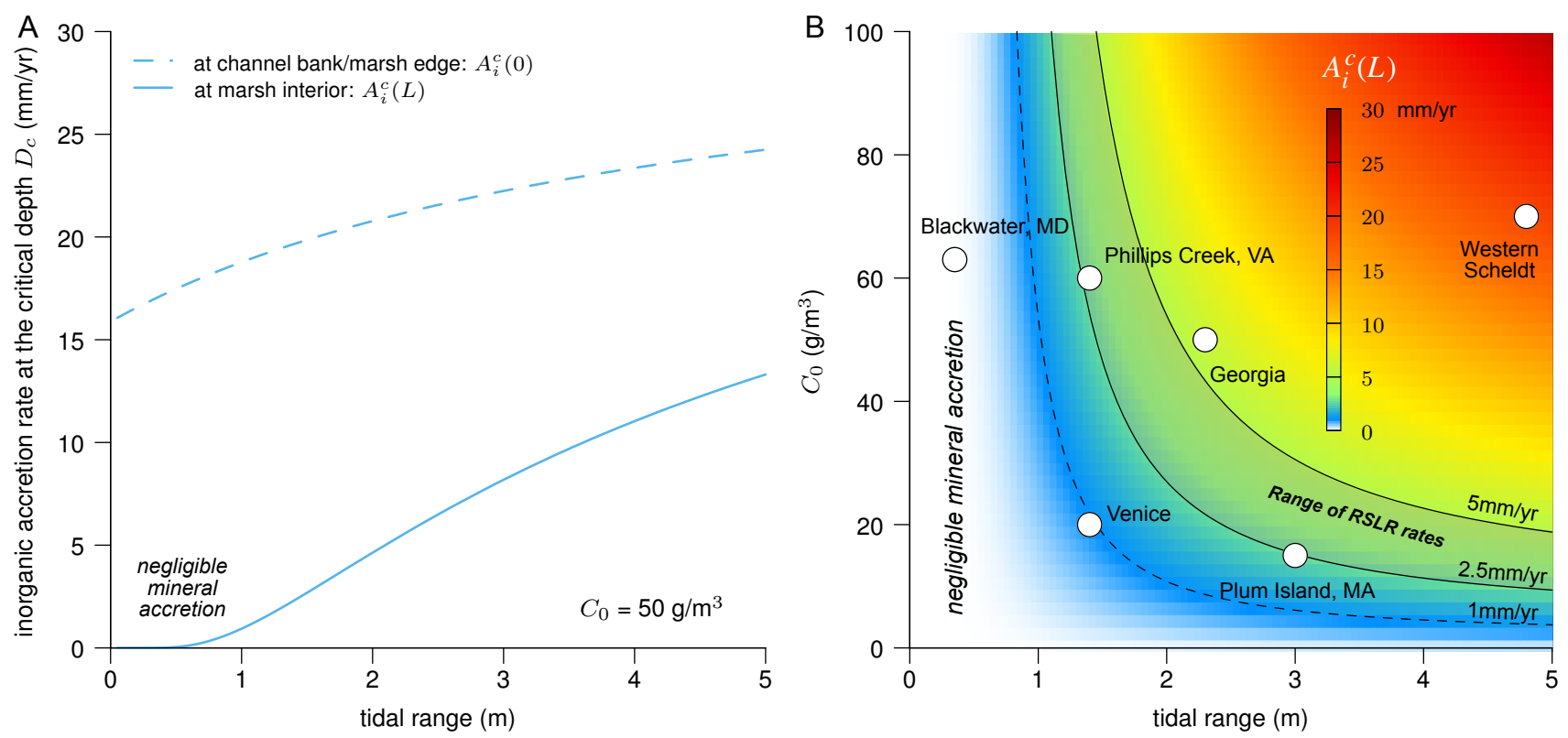

Figure 4. Predictions of critical inorganic accretion rates. (A) Inorganic accretion rates at the critical depth $D_{c}$ evaluated at the marsh edge and marsh interior $\left(A_{i}^{c}(0)\right.$ and $A_{i}^{c}(L)$, respectively) as function of tidal ranges for an average suspended sediment concentration at the channel bank of $C_{0}=50 \mathrm{~g} / \mathrm{m}^{3}$. We use $w_{f}=10^{-4} \mathrm{~m} / \mathrm{s}$, which is within commonly reported ranges ${ }^{3,22,64}$ and $\rho_{i}=2 \mathrm{~g} / \mathrm{cm}^{3}$, obtained from a meta-analysis of bulk density measurements in global marshes ${ }^{1}$. (B) Color map of the critical inorganic accretion rate at the marsh interior $A_{i}^{c}(L)$ as function of tidal range and average SSC at the channel bank $\left(C_{0}\right)$. Black lines separate regions with low inorganic deposition in the marsh interior $\left(A_{i}^{c}(L)<1 \mathrm{~mm} / \mathrm{yr}\right.$, dashed line) and with inorganic deposition lower than a common range of global rates of $\mathrm{RSLR}\left(A_{i}^{c}(L)<2.5-5 \mathrm{~mm} / \mathrm{yr}\right.$, solid lines). Superimposed data: Venice, Italy ${ }^{3}$; Western Scheldt, NL ${ }^{64}$; from USA: Blackwater, MD $^{33}$; Plum Island, MA ${ }^{42,51}$; Phillips Creek, VA $^{22,34}$; Georgia ${ }^{35}$. 

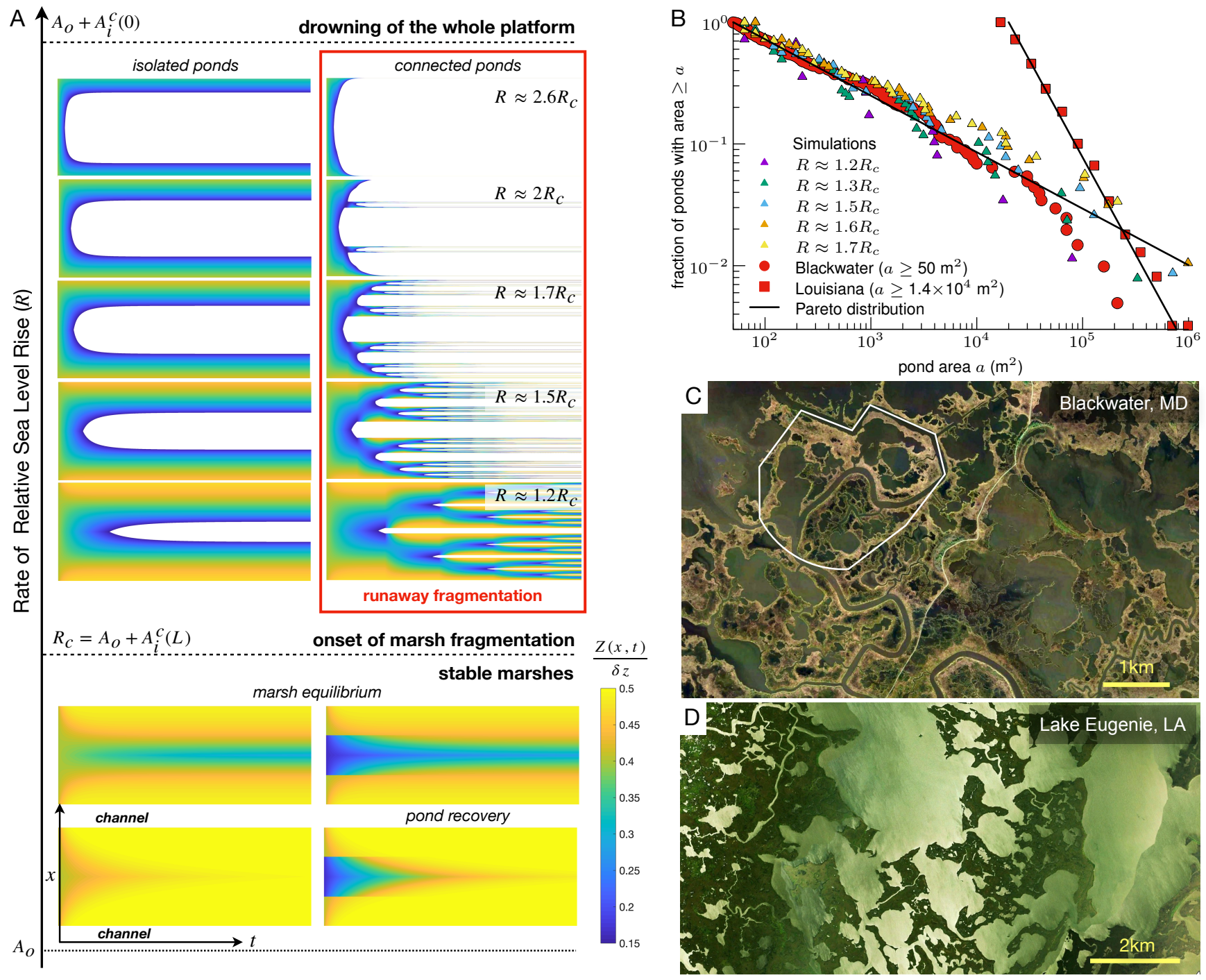

Figure 5. Marsh equilibrium states and runaway marsh fragmentation. (A) One-dimensional spatio-temporal plots of simulated marsh elevation $Z(x, t)$ (in color) for different rates $R$ of RSLR starting from a flat marsh platform flanked by channels on both sides (see Methods for model description and parameters). For each rectangle, $x$ runs vertically from channel to channel and $t$ runs from left to right (see bottom left illustration). Elevations below the critical value $Z_{c} / \delta z=0.15$ (corresponding to $D_{c} / \delta z=0.35$ ) are shown in white and represent ponds. For $R<R_{c}$, shallow ponds can recover (bottom center) and marshes reach a non-flat equilibrium state. For $R>R_{c}$, marsh drowns and form ponds. If those ponds remain isolated, the marsh eventually reaches equilibrium. Otherwise, a self-similar mechanism of pond formation and basin reduction leads to a runaway marsh fragmentation. (B) Exceedance probability distribution of pond areas in Blackwater, MD (representing ponds larger than $50 \mathrm{~m}^{2}$ within the white region in (C), see ${ }^{55}$ for details on data acquisition, data available in Table S2) and Louisiana (reported ponds larger than $1.4 \times 10^{4} \mathrm{~m}^{2}$ obtained from 1982-1985 composite satellite images ${ }^{56}$ ). The distribution of simulated ponds $(\mathrm{A})$ (with pond area defined as the square of its length) is shown for comparison. The distribution of pond area is consistent with a Pareto (power-law) distribution (linear fits), with power 1.46 for Blackwater, 2.6 for Louisiana and $\sim 1.5$ for the simulations. (C-D) Examples of apparently self-similar patterns from marshes in Blackwater, MD and around Lake Eugenie, Louisiana. 


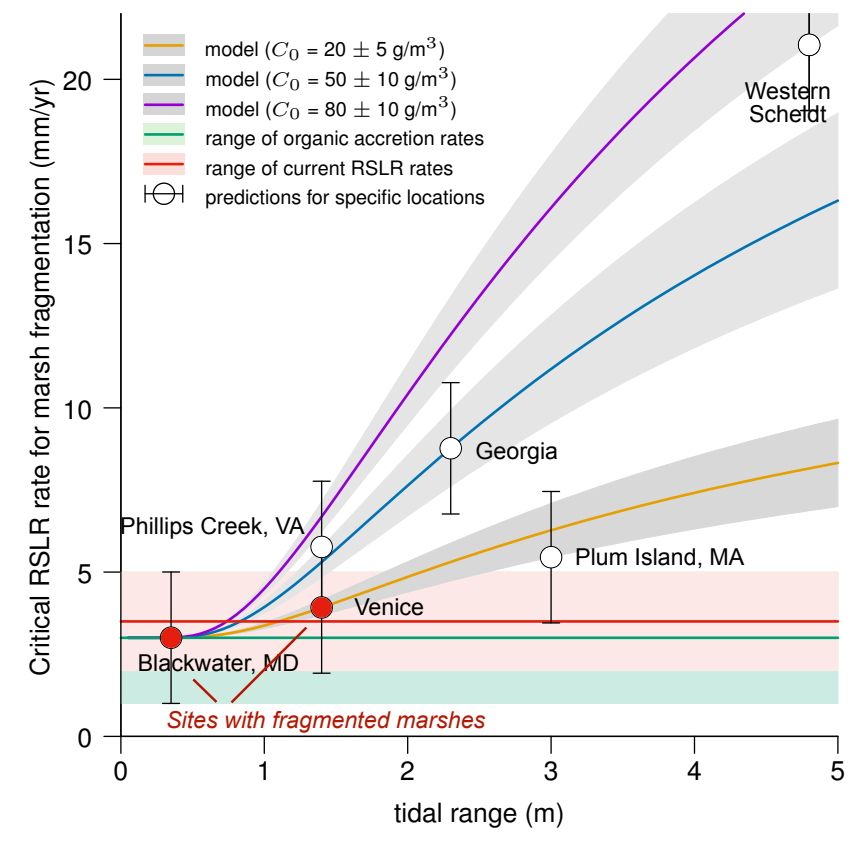

Figure 6. Threshold rates for runaway marsh fragmentation. Lines are predicted thresholds for marsh fragmentation $\left(R_{c}=A_{o}^{c}+A_{i}^{c}(L)\right)$ as function of tidal range, for different values of the average suspended sediment concentration at the channel bank $C_{0}$ representing typical low, mid and high sediment supply conditions (see Fig. 4B). We use $w_{f}=10^{-4} \mathrm{~m} / \mathrm{s}$ and $\rho_{i}=2 \mathrm{~g} / \mathrm{cm}^{3}$ for the calculation of the critical inorganic accretion $A_{i}^{c}(L)$ (as in Fig. 4), and assume an organic accretion rate $A_{o}^{c}=3 \mathrm{~mm} / \mathrm{yr}$, consistent with a meta-analysis of field data (Fig. S5 and Supplemental Experimental Procedures). Symbols represent predictions for specific locations including Blackwater, MD; Plum Island, MA; Phillips Creek, VA and Georgia (we use values shown in Fig. 4B). Current RSLR rates for those locations are in the range $3.5 \pm 1.5 \mathrm{~mm} / \mathrm{yr}$ (red line and shaded area). Organic accretion rates in salt marshes are in the range $3.0 \pm 2.0 \mathrm{~mm} / \mathrm{yr}$ (green line, shaded area and error-bars, see Fig. S5 and Supplemental Experimental Procedures). 

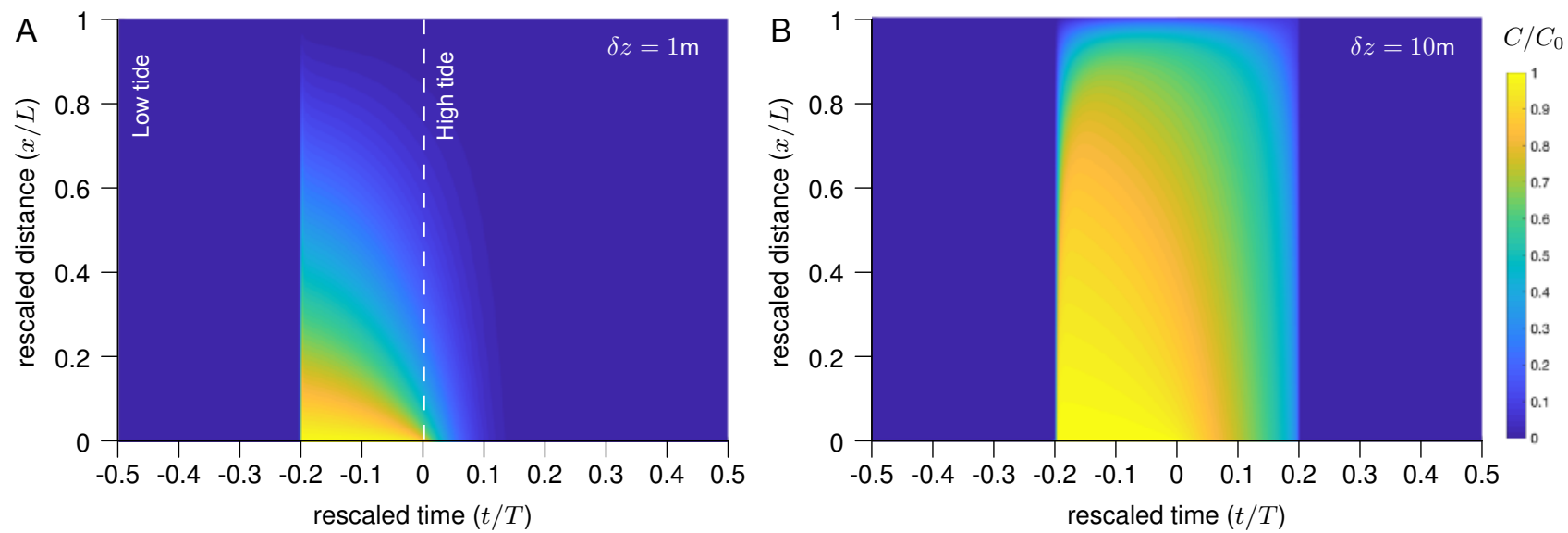

Figure S 1. Numerical solution of the rescaled depth-averaged sediment concentration $C / C_{0}$ over a flat marsh surface at a critical elevation $Z_{c}=0.15 \delta z$ (relative to mean sea level with tidal range $\delta z$ ) for two different rescaled effective falling velocity $w_{f}^{+}=w_{f} T / \delta z: w_{f}^{+}=4.5(\mathrm{~A})$ and $w_{f}^{+}=0.45(\mathrm{~B})$. Time is rescaled by tidal period $T=12.5 \mathrm{~h}$, and length by the distance $L$ to marsh edge. For $w_{f}=10^{-4} \mathrm{~m} / \mathrm{s}$, the corresponding tidal range $\delta z$ is $1 \mathrm{~m}(\mathrm{~A})$ and $10 \mathrm{~m}$ (B).

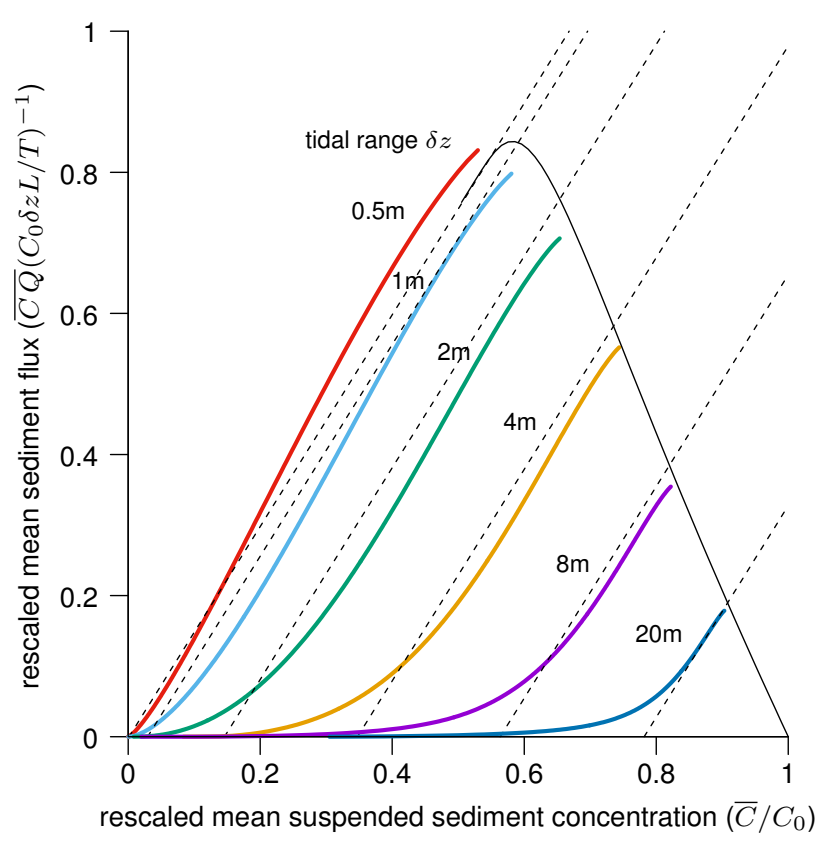

Figure S 2. Correlation between the rescaled depth-integrated sediment flux $\overline{C Q} \bar{Q}^{+}=\overline{C Q} /\left(C_{0} \delta z L T^{-1}\right)$ and the rescaled depth-averaged sediment concentration $\bar{C}^{+}=\bar{C} / C_{0}$, both averaged over times of positive water depths, for different rescaled effective falling velocity $w_{f}^{+}=w_{f} T / \delta z$ (parametrized by a variable tidal range $\delta z$ for constant $w_{f}$ ). Dashed lines show the linear approximation $\overline{Q C}^{+} \approx \beta\left[\bar{C}^{+}-\bar{C}^{+}(L)\right]$ with fitting constant $\beta=1.5$ and where $\bar{C}^{+}(L)=\bar{C}^{+}(0) e^{-w_{f}^{+} / \beta}$ is the rescaled concentration at the watershed divide $x=L$. Solid lines show the approximated maximum rescaled average sediment flux at marsh edge $(x=0)$, given by the relation $\overline{Q C}^{+}(0)=\beta\left[\bar{C}^{+}(0)-\bar{C}^{+}(L)\right]$, where both $\bar{C}^{+}(0)$ and $\bar{C}^{+}(L)$ are function of tidal range via the rescaled falling velocity $w_{f}^{+}$(See Fig. S3). Simulation data is shown only for the critical elevation $Z_{c}=0.15 \delta z$, but a similar result is obtained for any other elevation. 


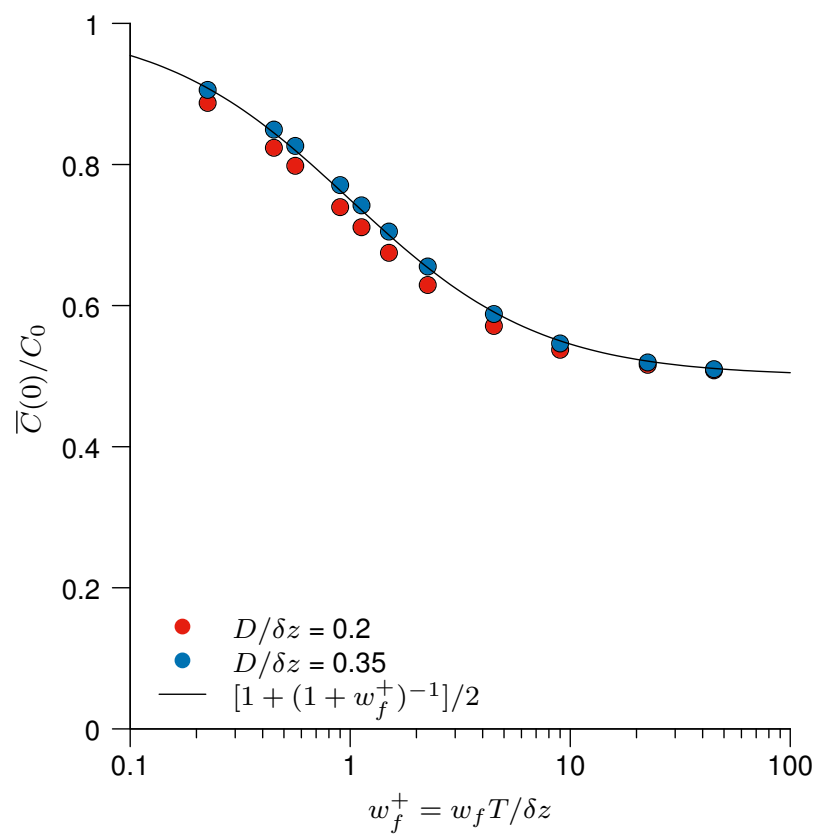

Figure S 3. The depth-averaged sediment concentration at marsh edge $\bar{C}(0)$, averaged over times with positive water depth, depends weakly on the rescaled marsh depth and has the form $\bar{C}(0)=C_{0} r\left(w_{f}^{+}\right)$. The solid line shows the fitted function $r\left(w_{f}^{+}\right)=\left(1+\left(1+w_{f}^{+}\right)^{-1}\right) / 2$.

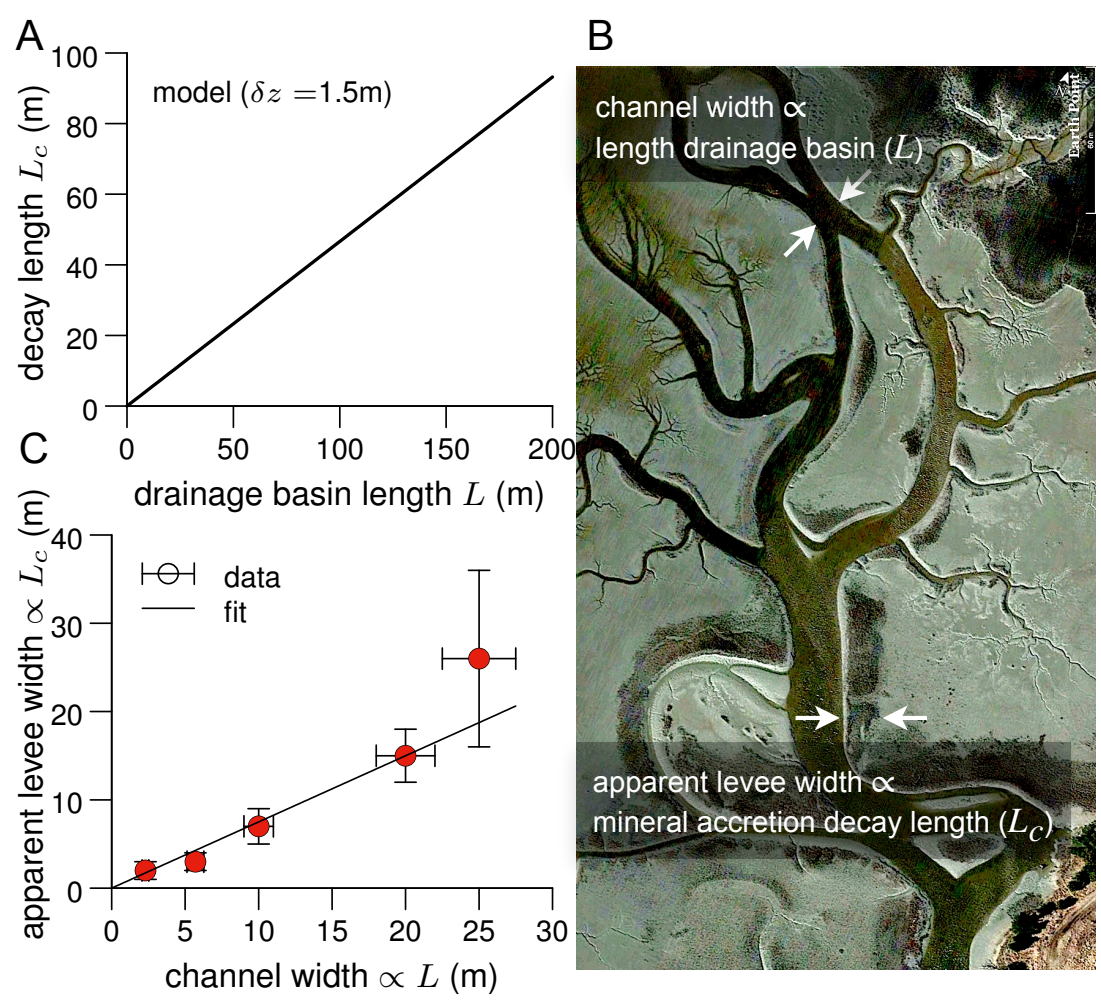

Figure S 4. Evidence of the scale invariance of inorganic deposition. (A) Scaling of the decay length $L_{c}$ and the drainage basin length $L$ predicted by the analytical model. (B) Tidal channel network in Phillips Creek, VA, USA, showing the apparent width of the levees (darker areas surrounding the channels) increasing with channel width, which suggests sediment deposits in a wider region for larger tidal flows. (C) Linear scaling obtained from the analysis of (B). 


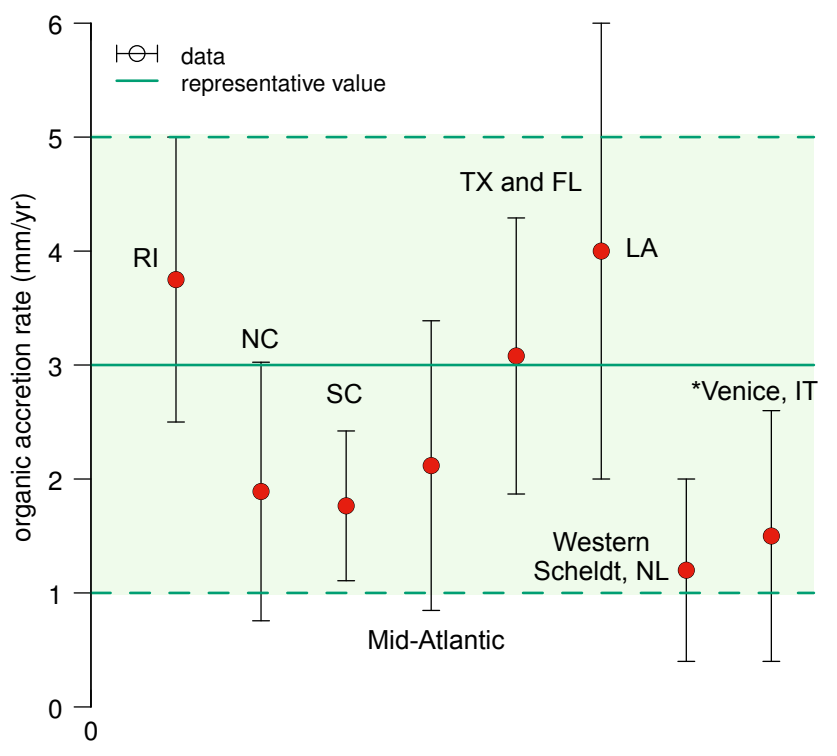

Figure S 5. Approximate range of organic accretion rates. Organic accretion rates estimated from field data are within $1-5 \mathrm{~mm} / \mathrm{yr}$ (shadow area). Solid line shows a theoretical maximum for salt marshes ${ }^{1}$ (representative value). Field data: Rhodes Island $(\mathrm{RI})^{2}$; North Carolina $(\mathrm{NC})^{3}$; South Carolina (SC) ${ }^{3}$; US Mid-Atlantic average ${ }^{3}$; Texas and Florida (TX \& FL) ${ }^{3}$; Louisiana (LA $)^{4}$; Western Scheldt, $\mathrm{NL}^{5}$; Venice, Italy (see Supplemental Experimental Procedures for details). 


\begin{tabular}{|c|c|c|c|}
\hline Location & $\begin{array}{l}\text { tidal range } \\
\qquad \delta z(\mathrm{~m})\end{array}$ & $D_{c} / \delta z$ & Reference \\
\hline Blackwater, MD & 0.5 & $0.4 \pm 0.2$ & $\begin{array}{l}D_{c}=\delta z / 2-Z_{c} \approx 0.2 \pm 0.1 \mathrm{~m}, \text { where } Z \approx 0.05 \pm 0.1 \mathrm{~m} \text { is the } \\
\text { cross-over elevation between bare patches and vegetated } \\
\text { ones, } 6 \text {. The uncertainty is approximated by the differ- } \\
\text { ence between the typical elevation of bare patches and } \\
\text { vegetated areas }{ }^{6} .\end{array}$ \\
\hline San Felice, Venice & 1.0 & $0.35 \pm 0.1$ & $\begin{array}{l}D_{c}=\delta z / 2-Z_{c} \approx 0.35 \pm 0.1 \mathrm{~m}, \text { where } Z_{c} \approx 0.15 \pm 0.1 \mathrm{~m} \text { is } \\
\text { the cross-over elevation between connected bare patches } \\
\text { and vegetated ones }{ }^{6} \text {. This choice is consistent with the } \\
\text { elevation above which marshes are generally found in the } \\
\text { Venice lagoon, in the range } 0.1-0.2 \mathrm{~m}^{7,8} \text {. The uncertainty } \\
\text { is approximated by the difference between the typical ele- } \\
\text { vation of connected bare patches and vegetated areas }{ }^{6} \text {. }\end{array}$ \\
\hline Plum Island, MA & 3 & $0.40 \pm 0.04$ & $\begin{array}{l}D_{c}=\delta z / 2-Z_{c} \approx 1.2 \mathrm{~m}, \text { where } Z_{c}=0.31 \mathrm{~m} \text { is the eleva- } \\
\text { tion (above MSL) of the lowest-elevation bare pool re- } \\
\text { ported }{ }^{9} \text { (Duncan's pool, site R-20 in Morris Island). The } \\
\text { uncertainty is the difference in elevation between Dun- } \\
\text { can's pool and the next low-elevation revegetating pool } \\
\left(Z=0.42 \mathrm{~m} \text { above MSL, site RRP-2 in Law's Point }{ }^{9}\right) \text {. Thus } \\
\Delta D_{c}=\Delta Z_{c}=0.1 \mathrm{~m} \text {. }\end{array}$ \\
\hline $\begin{array}{l}\text { Hallegat and Paulina } \\
\text { marshes, NL }\end{array}$ & 4.8 & $0.40 \pm 0.06$ & $\begin{array}{l}\text { Marsh recovery characterized by a critical value of average } \\
\text { rescaled inundation time, } \tau_{c}=0.44 \pm 0.02^{10} \text {. Assuming a } \\
\text { constant tidal range, the rescaled inundation time } \tau(D) \text { at } \\
\text { a depth } D \text { can be written as } \tau(D) \approx \pi^{-1} \text { arccos }(1-2 D / \delta z) \text {. } \\
\text { Therefore, the rescaled critical depth is } D_{c} / \delta z=0.5(1- \\
\left.\cos \left(\pi \tau_{c}\right)\right) \approx 0.40 \pm 0.03 \text {. We double the uncertainty to ac- } \\
\text { count for a broader region (depth) of marsh vulnerability }{ }^{10} \text {. }\end{array}$ \\
\hline Western Scheldt, NL & 4.9 & $0.3 \pm 0.1$ & $\begin{array}{l}\text { Estimation from the reported occurrence probability of pio- } \\
\text { neer plants patches }{ }^{11} \text {, which is between } 0-1 \% \text { for depths } \\
\text { in the range } 1-2 \mathrm{~m}^{11} \text {. Thus } D_{c}=1.5 \pm 0.5 \mathrm{~m} \text {. }\end{array}$ \\
\hline
\end{tabular}

Table S 1. Estimation of the rescaled critical depth for marsh recovery $\left(D_{c} / \delta z\right)$ shown in Fig. $1 \mathrm{~B}$. By definition, $Z_{c}=\delta z / 2-D_{c}$ is the critical elevation relative to MSL. 


\begin{tabular}{|c|c|c|c|c|c|c|c|c|c|}
\hline \# & $A$ & \# & A & \# & $A$ & $\#$ & A & \# & $A\left(\mathrm{~m}^{2}\right)$ \\
\hline 1 & 50 & 51 & 89 & 101 & 211 & 151 & 1301 & 201 & 158637 \\
\hline 2 & 52 & 52 & 89 & 102 & 221 & 152 & 1314 & 202 & 212723 \\
\hline 3 & 52 & 53 & 91 & 103 & 222 & 153 & 1360 & 203 & 230824 \\
\hline 4 & 54 & 54 & 92 & 104 & 223 & 154 & 1367 & & \\
\hline 5 & 55 & 55 & 92 & 105 & 223 & 155 & 1370 & & \\
\hline 6 & 55 & 56 & 92 & 106 & 227 & 156 & 1470 & & \\
\hline 7 & 56 & 57 & 94 & 107 & 236 & 157 & 1524 & & \\
\hline 8 & 56 & 58 & 100 & 108 & 248 & 158 & 1605 & & \\
\hline 9 & 56 & 59 & 101 & 109 & 250 & 159 & 1679 & & \\
\hline 10 & 57 & 60 & 106 & 110 & 254 & 160 & 1699 & & \\
\hline 11 & 57 & 61 & 106 & 111 & 268 & 161 & 1820 & & \\
\hline 12 & 57 & 62 & 108 & 112 & 272 & 162 & 2137 & & \\
\hline 13 & 59 & 63 & 109 & 113 & 276 & 163 & 2510 & & \\
\hline 14 & 59 & 64 & 110 & 114 & 289 & 164 & 2519 & & \\
\hline 15 & 59 & 65 & 114 & 115 & 318 & 165 & 2554 & & \\
\hline 16 & 60 & 66 & 114 & 116 & 320 & 166 & 2998 & & \\
\hline 17 & 60 & 67 & 115 & 117 & 326 & 167 & 3134 & & \\
\hline 18 & 61 & 68 & 119 & 118 & 329 & 168 & 3300 & & \\
\hline 19 & 61 & 69 & 122 & 119 & 387 & 169 & 3435 & & \\
\hline 20 & 64 & 70 & 123 & 120 & 393 & 170 & 3508 & & \\
\hline 21 & 64 & 71 & 125 & 121 & 415 & 171 & 3656 & & \\
\hline 22 & 64 & 72 & 129 & 122 & 428 & 172 & 3695 & & \\
\hline 23 & 64 & 73 & 130 & 123 & 429 & 173 & 3730 & & \\
\hline 24 & 65 & 74 & 130 & 124 & 447 & 174 & 4071 & & \\
\hline 25 & 65 & 75 & 133 & 125 & 449 & 175 & 4174 & & \\
\hline 26 & 65 & 76 & 135 & 126 & 452 & 176 & 4303 & & \\
\hline 27 & 67 & 77 & 135 & 127 & 453 & 177 & 4335 & & \\
\hline 28 & 67 & 78 & 135 & 128 & 541 & 178 & 4384 & & \\
\hline 29 & 69 & 79 & 139 & 129 & 544 & 179 & 4428 & & \\
\hline 30 & 70 & 80 & 139 & 130 & 558 & 180 & 4714 & & \\
\hline 31 & 70 & 81 & 140 & 131 & 599 & 181 & 5514 & & \\
\hline 32 & 71 & 82 & 140 & 132 & 608 & 182 & 6331 & & \\
\hline 33 & 71 & 83 & 142 & 133 & 612 & 183 & 6537 & & \\
\hline 34 & 73 & 84 & 144 & 134 & 614 & 184 & 6551 & & \\
\hline 35 & 73 & 85 & 144 & 135 & 678 & 185 & 7713 & & \\
\hline 36 & 74 & 86 & 149 & 136 & 720 & 186 & 8132 & & \\
\hline 37 & 74 & 87 & 152 & 137 & 772 & 187 & 9022 & & \\
\hline 38 & 74 & 88 & 156 & 138 & 844 & 188 & 9325 & & \\
\hline 39 & 74 & 89 & 161 & 139 & 856 & 189 & 9986 & & \\
\hline 40 & 75 & 90 & 163 & 140 & 907 & 190 & 13973 & & \\
\hline 41 & 76 & 91 & 166 & 141 & 912 & 191 & 22799 & & \\
\hline 42 & 77 & 92 & 169 & 142 & 957 & 192 & 29843 & & \\
\hline 43 & 79 & 93 & 181 & 143 & 967 & 193 & 30100 & & \\
\hline 44 & 80 & 94 & 184 & 144 & 976 & 194 & 34837 & & \\
\hline 45 & 81 & 95 & 192 & 145 & 1097 & 195 & 38968 & & \\
\hline 46 & 82 & 96 & 195 & 146 & 1135 & 196 & 40827 & & \\
\hline 47 & 82 & 97 & 198 & 147 & 1137 & 197 & 55439 & & \\
\hline 48 & 85 & 98 & 206 & 148 & 1188 & 198 & 70379 & & \\
\hline 49 & 85 & 99 & 208 & 149 & 1249 & 199 & 70465 & & \\
\hline 50 & 88 & 100 & 209 & 150 & 1285 & 200 & 89557 & & \\
\hline
\end{tabular}

Table S 2. List of measured pond areas $\left(A\right.$ in $\left.\mathrm{m}^{2}\right)$ of ponds above $50 \mathrm{~m}^{2}$ from a 2010 aerial image of Blackwater marshes (MD) ${ }^{12}$ (see location of the selected region in Fig. 5C). Data used in Fig. 5B. 


\section{Supplemental Experimental Procedures}

\section{Organic accretion rates}

For some locations in USA (North and South Carolina, Mid-Atlantic and Texas \& Florida) we used the data compilation from $^{3}$, which reports the total accretion rate range (min and max values) and the slope $\left(\mathrm{cm}^{3} \mathrm{~g}^{-1}\right)$ of the linear regression between organic mass accretion rates (defined as the dependent variable, $\mathrm{g} \mathrm{cm}^{-3} \mathrm{yr}^{-1}$ ) and total accretion rates (defined as the independent

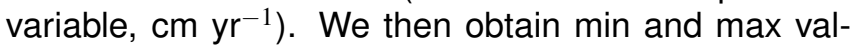
ues for organic mass accretion rates and convert them from mass to volume using an effective density of deposited organic matter: $\rho_{o}=0.085 \mathrm{~g} / \mathrm{cm}^{3}$, obtained from a meta-analysis of bulk density measurements in global marshes ${ }^{1}$. For Rhodes Island, US, we use reported values of organic mass accretion rates ${ }^{2}$ converted to volume using $\rho_{o}$. We did the same for some marshes in Louisiana, US ${ }^{4}$. We also used reported values of organic accretion rates $(\mathrm{mm} / \mathrm{yr})$ for some locations in the Scheldt estuary, $\mathrm{NL}^{5}$. For Venice, we estimate organic accretion rates from reported total marsh accretion rates ${ }^{13}$, using the average bulk density $\approx 1 \mathrm{~g} / \mathrm{cm}^{314}$ and the effective values for the density of organic and inorganic deposited sediments $\rho_{i}=2 \mathrm{~g} / \mathrm{cm}^{3}$ and $\rho_{o}=0.085 \mathrm{~g} / \mathrm{cm}^{3}$ respectively ${ }^{1}$. The organic accretion rate data is shown in Fig. S5.

\section{Supplemental References}

1. Morris, J. T., Barber, D. C., Callaway, J. C., Chambers, R., Hagen, S. C., Hopkinson, C. S., Johnson, B. J., Megonigal, P., Neubauer, S. C., Troxler, T. \& Wigand, C. (2016). Contributions of organic and inorganic matter to sediment volume and accretion in tidal wetlands at steady state: Sediment bulk density and ignition loss. Earth's Futur. 4, 110-121, 10.1002/2015EF000334.

2. Bricker-Urso, S., Nixon, S. W., Cochran, J. K., Hirschberg, D. J. \& Hunt, C. (1989). Accretion rates and sediment accumulation in Rhode Island salt marshes. Estuaries 12, 300-317, 10.2307/1351908.

3. Turner, R. E., Swenson, E. M. \& Milan, C. S. Organic and Inorganic Contributions to Vertical Accretion in Salt Marsh Sediments. In Concepts and Controversies in Tidal Marsh Ecology, 583595, 10.1007/0-306-47534-027 (Springer, Dordrecht, 2002).

4. DeLaune, R. D., Whitcomb, J. H., Patrick, W. H., Pardue, J. H. \& Pezeshki, S. R. (1989). Accretion and canal impacts in a rapidly subsiding wetland. I. $137 \mathrm{Cs}$ and $210 \mathrm{~Pb}$ techniques. Estuaries Coasts 12, 247-259.

5. Temmerman, S., Govers, G., Wartel, S. \& Meire, P. (2004). Modelling estuarine variations in tidal marsh sedimentation: response to changing sea level and suspended sediment concentrations. Mar. Geol. 212, 1-19, 10.1016/j.margeo.2004.10.021.

6. Wang, C., Schepers, L., Kirwan, M. L., Belluco, E., D'Alpaos, A., Wang, Q., Yin, S. \& Temmerman, S. (2021). Different coastal marsh sites reflect similar topographic conditions under which bare patches and vegetation recovery occur. Earth Surf. Dyn. 9, 71-88, 10.5194/esurf-9-71-2021.

7. Fagherazzi, S., Carniello, L., D’Alpaos, L. \& Defina, A. (2006). Critical bifurcation of shallow microtidal landforms in tidal flats and salt marshes. Proc. Natl. Acad. Sci. United States Am. 103, 8337-41, 10. 1073/pnas.0508379103.

8. Defina, a., Carniello, L., Fagherazzi, S. \& D’Alpaos, L. (2007). Self-organization of shallow basins in tidal flats and salt marshes. J. Geophys. Res. 112, F03001-F03001, 10.1029/2006JF000550.

9. Wilson, C. A., Hughes, Z. J., FitzGerald, D. M., Hopkinson, C. S., Valentine, V. \& Kolker, A. S. (2014). Saltmarsh pool and tidal creek morphodynamics: Dynamic equilibrium of northern latitude saltmarshes? Geomorphology 213, 99-115, 10.1016/j.geomorph.2014.01.002.

10. van Belzen, J., van de Koppel, J., Kirwan, M. L., van der Wal, D., Herman, P. M. J., Dakos, V., Kéfi, S., Scheffer, M., Guntenspergen, G. R. \& Bouma, T. J. (2017). Vegetation recovery in tidal marshes reveals critical slowing down under increased inundation. Nat. Commun. 8, 15811, 10.1038/ncomms15811.

11. Wang, C. \& Temmerman, S. (2013). Does biogeomorphic feedback lead to abrupt shifts between alternative landscape states?: An empirical study on intertidal flats and marshes. J. Geophys. Res. Earth Surf. 118, 229-240, 10.1029/2012JF002474.

12. Himmelstein, J. D. Mechanisms of Pond Expansion on the Saltmarshes of the Blackwater National Wildlife Refuge, Maryland. Master's thesis, The College of William and Mary (2018).

13. Bellucci, L., Frignani, M., Cochran, J., Albertazzi, S., Zaggia, L., Cecconi, G. \& Hopkins, H. (2007). $210 \mathrm{pb}$ and $137 \mathrm{cs}$ as chronometers for salt marsh accretion in the Venice Lagoon - links to flooding frequency and climate change. J. Environ. Radioact. 97, 85-102, 10.1016/j.jenvrad.2007.03.005.

14. Roner, M., D'Alpaos, A., Ghinassi, M., Marani, M., Silvestri, S., Franceschinis, E. \& Realdon, N. (2016). Spatial variation of salt-marsh organic and inorganic deposition and organic carbon accumulation: Inferences from the Venice lagoon, Italy. Adv. Water Resour. 93, Part B, 276-287, 10.1016/j.advwatres.2015.11.011. 